\title{
Donor-Acceptor Molecular Oligogermanes: Novel Properties and Structural Aspects
}

\author{
Kirill V. Zaitsev, ${ }^{*, a}$ Kevin Lam, ${ }^{*, b}$ Andrei V. Churakov, ${ }^{*, c}$ Anastasia V. Kharcheva, ${ }^{*, a}$ Yuri

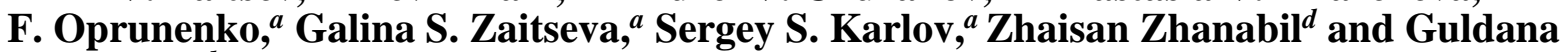 \\ Issabayeva $^{d}$
}

${ }^{a}$ Department of Chemistry, Moscow State University, Leninskye Gory 1, Moscow 119991, Russia. Fax: +7(495)932 8846; Tel: +7(495)939 3887

${ }^{b}$ Department of Pharmaceutical, Chemical and Environmental Sciences, Faculty of

Engineering and Science, University of Greenwich, Central Avenue, Chatham Maritime,

Chatham, Kent ME4 4TB, United Kingdom

${ }^{c}$ N.S. Kurnakov General and Inorganic Chemistry Institute, Russian Academy of Sciences, Leninskii pr., 31, Moscow, Russia

${ }^{d}$ Department of Chemistry, Nazarbayev University, 53 Kabanbay Batyr Avenue, 010000 Astana, Republic of Kazakhstan

E-mail: akharcheva@or.chem.msu.ru (AVK); churakov@igic.ac.ru $(A V C)$;

zaitsev@org.chem.msu.ru (KVZ); k.lam@greenwich.ac.uk(KL)

\section{J. Organomet.Chem. Special Issue: "Organometallic Chemistry in Russia".}

This article is dedicated to Prof. Irina P. Beletskaya in recognition of her merits in the field of the chemistry of organoelement compounds.

Abstract: The linear oligogermyl amide 2, $\mathrm{Ph}_{3} \mathrm{GeGeMe}_{2} \mathrm{NMe}_{2}$, was obtained by reacting $\mathrm{Ph}_{3} \mathrm{GeLi}$ with $\mathbf{1}, \mathrm{Me}_{2} \mathrm{Ge}(\mathrm{Cl}) \mathrm{NMe}_{2}$. The amide 2 was used for the synthesis of molecular oligogermanes 3, $\mathrm{Ph}_{3} \mathrm{GeGeMe}{ }_{2} \mathrm{Ge}\left(\mathrm{C}_{6} \mathrm{~F}_{5}\right)_{3}$, and 4, $\left[\mathrm{Ph}_{3} \mathrm{GeGeMe}_{2}\right]_{2} \mathrm{Ge}\left(\mathrm{C}_{6} \mathrm{~F}_{5}\right)_{2}$, containing electron donor $(\mathrm{Me}, \mathrm{Ph})$ and acceptor $\left(\mathrm{C}_{6} \mathrm{~F}_{5}\right)$ groups, by using a hydrogermolysis reaction in $n$-hexane. The molecular structures of $\mathbf{3}$ and $\mathbf{4}$ were studied by XRD. It was shown that, in its crystal form, 3 forms wide channels, in which the solvated nonpolar $n$-hexane molecule is present. The NMR $\left({ }^{1} \mathrm{H},{ }^{13} \mathrm{C}\right.$ and ${ }^{19} \mathrm{~F}$ ), optical (UV/vis absorption, luminescence) and electrochemical (cyclic voltammetry) properties of both compounds were also studied. The impact of the substitution type (at the end of the compound, such as in $\mathbf{3}$, or within the compound, such as in $\mathbf{5}$, on the physical properties was also studied.

Keywords: oligogermane, main group metal chemistry, element - element bond, donor, acceptor, luminescence, X-ray diffraction analysis

\section{Introduction}

Recently, a recent interest has risen for the study of molecular catenated derivatives of Group 14 elements. This phenomenon is driven not only by a pure academic interest ${ }^{[1]}$, but also by the need for seeking for new useful properties for those compounds ${ }^{[2]}$. In these compounds 
the bonding electrons on HOMO orbitals (mainly $\mathrm{sp}^{3}$ hybridized) are delocalized along the M-M chain, this phenomenon is known as $\sigma$-conjugation between the $\mathrm{M}$ atoms. This makes catenated compounds (saturated compounds) analogous to alkenes in which special useful properties (intensive UV/vis absorbance, luminescence, electrochemical properties, non-linear properties, conductivity etc.) are observed. Among all catenated compounds, $\mathrm{Si}{ }^{[3]}$ and $\mathrm{Sn}{ }^{[4]}$ derivatives have been intensively investigated. Surprisingly, the Ge derivatives [5] have been rarely investigated. This might be explained by the synthetic challenge that those compounds represent.. The main challenge in the chemistry of oligogermanes is to be able to prepare a specific structure for a specific application. Therefore, it is crucial to study the impact of the structure of the oligogermane on its physical properties.. Furthermore, several polymeric germanes ${ }^{[6]}$ are known, but their precise "structure - property" relationships are established have only been superficially investigated.

The synthesis of compounds bearing a Ge-Ge bond could be achieved in two main ways. In the first group of methods, a nucleophilic lithium germyl reagent is reacted with an electrophilic germane (Scheme 1, reaction A). The most significant contribution to development of this method for the preparation of Ge derivatives was made by Draeger [7], Castel ${ }^{[8]}$, Marschner ${ }^{[9]}$ et al. The main drawback of this reactions lies in the fact that the Ge-Ge bond is sensitive to strong nucleophiles (i.e. organolithium compounds) and very often, such reaction, leads to anuncontrolled processes due to partial substitution of organic groups at Ge atom ${ }^{[10]}$ or destruction of Ge-Ge bond ${ }^{[11]}$ (Scheme 1, reaction B). The latest side reaction is very typical for aromatic derivatives.

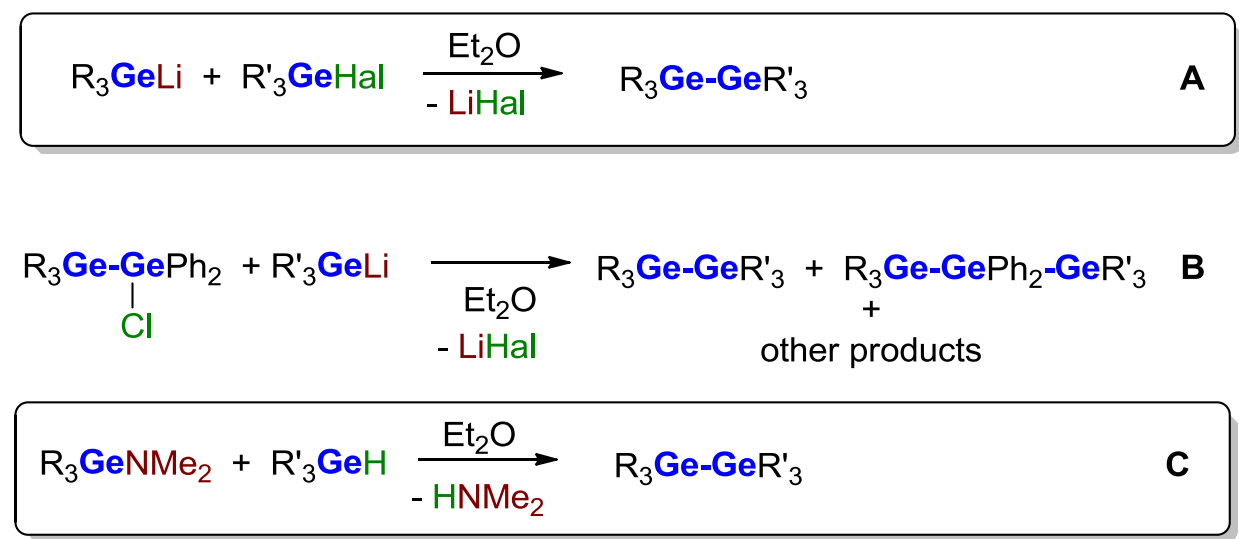

Scheme 1. General methods for creation the Ge-Ge bond.

A second way to prepare Ge-Ge building blocks is to react ta free germane with a germylamide under prolonged heating conditions (hydrogermolysis reaction) (Scheme 1, reaction $\mathrm{C}$ ). This reaction was initially developped for the synthesis of oligogermanes by Weinert et al. ${ }^{[12]}$. The main drawback of this method are the harsh conditions that are required as well as the sensitivity of the reaction to the steric volumes of the substituents. Furthermore, this method has been limited by the compatibility of some of the initial reagents. For instance, it is impossible to use geminal polyamides, $\mathrm{R}_{2} \mathrm{Ge}\left[\mathrm{NMe}_{2}\right]_{2}$, to construct the $\mathrm{Ge}-\mathrm{Ge}$ bond ${ }^{[13]}$. Although 
the corresponding vicinal diamides, $\mathrm{Me}_{2} \mathrm{NGePh}_{2} \mathrm{GePh}_{2} \mathrm{NMe}_{2}{ }^{[14]}$, and branched monoamides, $\left[\mathrm{Ph}_{3} \mathrm{Ge}\right]_{3} \mathrm{GeNMe}_{2}{ }^{[15]}$, are known and are sufficiently stable to be used under hydrogermolysis conditions, there is no data in the literature on using linear catenated germylmonoamide and their application in Ge-Ge bond formation. It could be expected that the synthesis of such compounds using strong nucleophiles like $\mathrm{LiNMe}_{2}$ would destroy the Ge-Ge bond analogously to the case stated above (Scheme 1, B). This is why the synthesis of oligogemyl monoamide may be regarded as interesting challenge.

It was previously established that the physical properties of the oligogermanes highly depend on the nature of the substituent, on their geometrical volume, on the number of Ge atoms in the chain and on the overall conformation of the molecule. Thus, the introduction of donating groups destabilize the HOMO ${ }^{[16]}$ level, whereas the presence of withdrawing groups resulted in a stabilization of the LUMO ${ }^{[10,13]}$, by improving the $\sigma$-conjugation. The same effect is observed when the Ge chain is elongated. The presence of voluminous groups on the Ge resulted in an elongation of Ge-Ge bond length. The effective conjugation is observed on the trans-coplanar configuration of Ge atoms in the chain ${ }^{[17]}$.. Therefore, the introduction of substituents with different electronic properties (electron donating and withdrawing) within the oligogermane molecule is expected to change its properties significantly.

In continuation of our works on molecular oligogermanes ${ }^{[1-2,10,13,18]}$ we are reporting on the synthesis and on the investigations of the properties of novel donor-acceptor compounds, 2 and 3. Their structure (NMR, XRD), optical (UV/vis absorbance, emission) and electrochemical properties were studied in detail.

\section{Results and Discussion}

\subsection{Synthesis}

0Hydrogermolysis is a best way for the synthesis of donor-acceptor oligogermanes as it was reported earlier ${ }^{[10]}$, since it leads to high yield of the desired compound, only gaseous byproducts and by almost absence of hardly separated impurities (especially in comparison with lithium reagents) usually, for the synthesis of germyl amides, the direct reaction between $\mathrm{R}_{3} \mathrm{GeHal}$ and $\mathrm{LiNMe}_{2}$ has been used earlier ${ }^{[10,19]}$. In this work a novel method for the synthesis of oligogermyl amide 2, $\mathrm{Ph}_{3} \mathrm{GeGeMe}_{2} \mathrm{NMe}_{2}$, is reported.. Compound $\mathbf{1}, \mathrm{Me}_{2} \mathrm{Ge}(\mathrm{Cl}) \mathrm{NMe}_{2}$, was obtained using a previously reported methodology (Scheme 1).

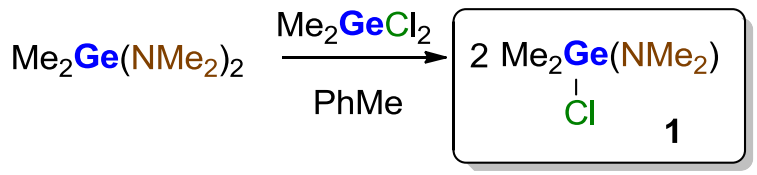

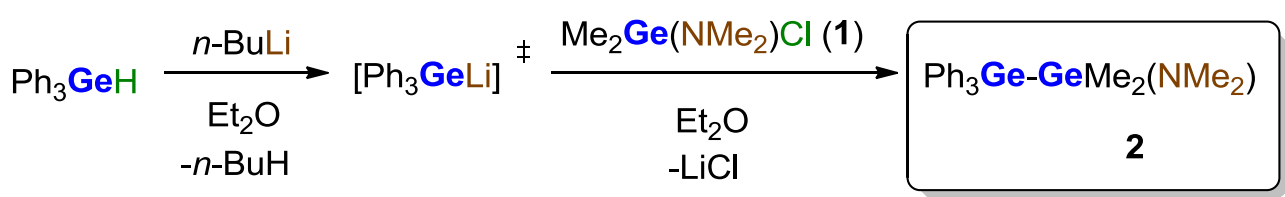

Scheme 2. Synthetic strategy for the synthesis of catenated germanium amides.

Compound $\mathbf{1}$ is known, but has not been fully characterized yet ${ }^{[20]}$. The known procedures for its synthesis reaction between gaseous $\mathrm{Me}_{2} \mathrm{NH}$ with $\mathrm{Me}_{2} \mathrm{GeCl}_{2}$ ) is very specific and not widely suitable for the laboratory synthesis. Thus, in this work, an optimal detailed 
procedure for the synthesis of $\mathbf{1}$ was elaborated using simple conditions and readily available starting material $\left.\left(\mathrm{Me}_{2} \mathrm{Ge}\left(\mathrm{NMe}_{2}\right)_{2}\right), \mathrm{Me}_{2} \mathrm{GeCl}_{2}\right)$.

Compound 2 is novel one; it was prepared by reaction $\mathrm{Ph}_{3} \mathrm{GeLi}$, generated in situ, with 1 . To the best of our knowledge, $\mathbf{2}$ is the first example of linear oligogermyl amide. The improved procedure for the synthesis of $\mathrm{Ph}_{3} \mathrm{GeH}$ is detailed in the experimental information (for details, see Experimental part).

Both compounds $\mathbf{1}$ and $\mathbf{2}$ are soluble in common organic solvents and are highly moisture sensitive.

For the synthesis of compounds $\mathbf{3}$ and $\mathbf{4}$ the hydrogermolysis reaction was used (Scheme 3 ). This reactions were performed in $n$-hexane, much to our surprise, using $\mathrm{MeCN}^{[12]}$ as a solvent revealed to be unsuccessful in this case and resulted only in the formation of an inseparable mixture of unidentified compounds.

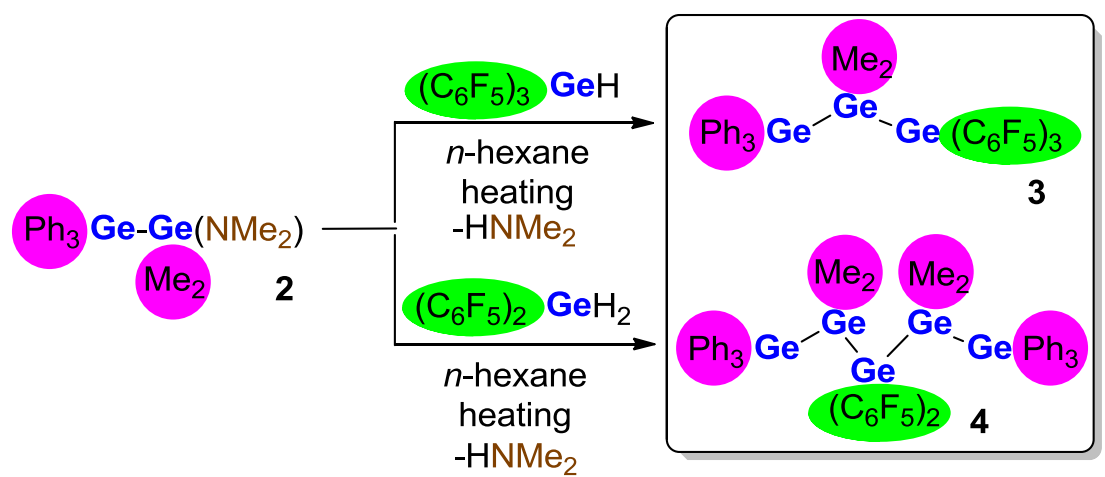

Scheme 3. Synthetic strategy for the synthesis of catenated germanium amides.

Compounds 3 and $\mathbf{4}$ were isolated as white air- and moisture stable powders in high yields (78 and $84 \%$, respectively). The structure of these compounds in solution was confirmed by multinuclear NMR spectroscopy $\left({ }^{1} \mathrm{H},{ }^{13} \mathrm{C},{ }^{19} \mathrm{~F}\right)$ and their composition was established on the basis of elemental analysis. In general, ${ }^{1} \mathrm{H}$ and ${ }^{13} \mathrm{C}$ NMR spectra for both compounds are very similar. The ${ }^{19} \mathrm{~F}$ NMR spectra show three signals (ortho-, para- and metha-) with integral intensities of 2:1:2, what indicates the free rotation of $\mathrm{C}_{6} \mathrm{~F}_{5}$ rings. The compounds bearing an end $\mathrm{C}_{6} \mathrm{~F}_{5}$ group $\left(\mathrm{Ph}_{3} \mathrm{GeGe}\left(\mathrm{C}_{6} \mathrm{~F}_{5}\right)_{3},(p-\mathrm{Tol})_{3} \mathrm{GeGe}\left(\mathrm{C}_{6} \mathrm{~F}_{5}\right)_{3}{ }^{[10]}\right.$ and 3$)$ have multiplet signals centered at $124,-149,-159 \mathrm{ppm}$, which means that the nature of the donating group and quantity of $\mathrm{Ge}$ atoms in the chain insignificantly impacts on the NMR spectra. At the same time, derivatives bearing median $\mathrm{C}_{6} \mathrm{~F}_{5}\left(\left[(p-\mathrm{Tol})_{3} \mathrm{Ge}\right]_{2} \mathrm{Ge}\left(\mathrm{C}_{6} \mathrm{~F}_{5}\right)_{2}{ }^{[10]}\right.$ and 4) have signals at -119/-121, -153/-152, 161/-159 ppm, which differ from the first case. It means that the substitution on the oligogermanes by withdrawing groups (end- or median in the chain) change the electronic structure of the whole molecule. The change of nature of donor groups (tolyl vs. phenyl) or amount of Ge atoms in the chain showed to be less dramatic.

\subsection{Molecular structure}

The molecular structures of compounds $\mathbf{3}$ and $\mathbf{4}$ in the solid state were investigated by single crystal X-ray diffraction analysis (Figs. 1, 3; Supporting Information, Table S1). 


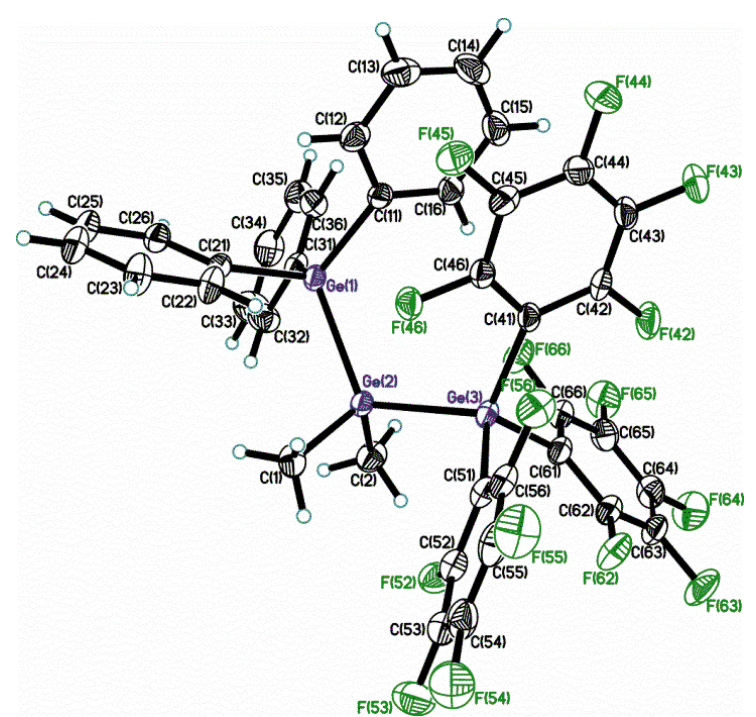

Fig. 1. Molecular structure of compound 3. Solvate molecule of $n$-hexane was not shown. Displacement ellipsoids are shown at $50 \%$ probability level. Selected bond lengths $(\AA)$ and bond angles (deg): $\mathrm{Ge}(1)-\mathrm{Ge}(2)$ 2.4475(4), $\mathrm{Ge}(2)-\mathrm{Ge}(3)$ 2.4522(4), $\mathrm{Ge}(1)-\mathrm{C}_{\mathrm{av}}$ 1.950(2), $\mathrm{Ge}(2)-\mathrm{C}_{\mathrm{av}}$ 1.958(3), $\mathrm{Ge}(3)-\mathrm{C}_{\mathrm{av}}$ 1.969(2); $\mathrm{Ge}(1)-\mathrm{Ge}(2)-\mathrm{Ge}(3)$ 115.780(14), C-Ge(1)-C $\mathrm{C}_{\mathrm{av}}$ 107.84(10), $\mathrm{Ge}(2)-$ $\mathrm{Ge}(1)-\mathrm{C}_{\mathrm{av}}$ 110.04(7), C(2)-Ge(2)-C(1) 107.99(12), Ge(1)-Ge(2)- $\mathrm{C}_{\mathrm{av}} 118.18(8), \mathrm{Ge}(3)-\mathrm{Ge}(2)-\mathrm{C}_{\mathrm{av}}$ 105.08(8), C-Ge(3)- $\mathrm{C}_{\mathrm{av}}$ 107.30(10), C-Ge(3)-Ge(2) $)_{\mathrm{av}} 111.54(7)$.

Up todayonly 12 linear molecular trigermanes have been studied by XRD (for details see ${ }^{[13]}$ ), where Ge-Ge bond length and Ge-Ge-Ge angle vary between 2.413-2.6223 $\AA$ and 110.4$125.00^{\circ}$, respectively, depending on the steric size and on the electronic nature of the substituents located at $\mathrm{Ge}$ atoms. Compound 3 crystallizes in the $\mathrm{P}-1$ space group $(\mathrm{Z}=2)$. The presence of a phenyl or a pentafluorophenyl group has a very limited impact on the on the length of $\mathrm{Ge}-\mathrm{Ge}$ bond (2.4475(4) vs. 2.4522(4) $\AA$ ), where the longer bond is typical for Ge containing electron withdrawing groups. At the same time the average Ge-Ge bond length in 3 is 2.4499(4) $\AA$, what is somewhat longer than what would could be expected for aryl sterically non-hindered groups (2.429(1) $\AA$ in $\left.\mathrm{Ph}_{3} \mathrm{GeGeMe}_{2} \mathrm{GePh}_{3}{ }^{[11 \mathrm{~b}]}\right)$. Furthermore, $d(\mathrm{Ge}(2)-\mathrm{Ge}(3))$ is shorter than in related donor-acceptor digermanes $\mathrm{Ph}_{3} \mathrm{GeGe}\left(\mathrm{C}_{6} \mathrm{~F}_{5}\right)_{3}(2.4623(4) \AA)$ and $(p \text {-Tol })_{3} \mathrm{GeGe}\left(\mathrm{C}_{6} \mathrm{~F}_{5}\right)_{3}(2.4652(11)$ $\AA{ }^{[10]}$, containing end substitution by perfluorophenyl groups. This could be explained by the decrease of the steric volume of the substituents ( $\mathrm{Me} v s$. Ph or Tol) and by the elongation of the Ge chain in 3.

It is interesting to compare the structural parameters of $\mathbf{3}$ with the ones of the donoracceptor trigermane $\left[(p-\mathrm{Tol})_{3} \mathrm{Ge}\right]_{2} \mathrm{Ge}\left(\mathrm{C}_{6} \mathrm{~F}_{5}\right)_{2}{ }^{[10]}$, containing median disposition of withdrawing groups in the molecule. The $\mathrm{Ge}-\mathrm{Ge}\left(\mathrm{C}_{6} \mathrm{~F}_{5}\right)$ bond lengths $(2.4522(4)$ vs. 2.459(5) $\AA$ ) and central CGe-C angle $\left(\mathrm{C}(2)-\mathrm{Ge}(2)-\mathrm{C}(1)\right.$ 107.99(12) vs. 108.0(2) $\left.{ }^{\circ}\right)$ are very similar, but Ge-Ge-Ge angle differs significantly $\left(115.780(14)\right.$ vs. $\left.124.10(3)^{\circ}\right)$, this shows the effect of the substitution (end or median) on the oligogermanium chain.

The geometry of Ge atoms may be described as a distorted tetrahedron, where the largest deviation from the ideal tetrahedral was observed for the central $\mathrm{Ge}(2)$ atom. In a crystal, the planes of one of the aromatic groups lie almost in parallel planes due to the electron stacking. The Ge-C bond length is slightly longer in the perfluorophenyl derivative possibly due to an increase of the steric volume. All phenyl rings are in propeller-like conformation in relation to 
the corresponding Ge-Ge bonds $\left(\mathrm{Ge}_{\mathrm{Me}}-\mathrm{Ge}_{\mathrm{Ar}} \mathrm{C}-\mathrm{C}\right.$ torsions are $42.81,50.45^{\circ}$ for $\mathrm{Ph}$ and 51.78 , $54.19^{\circ}$ for $\mathrm{C}_{6} \mathrm{~F}_{5}$ ), wherein the rings in stacking are deviated more significantly (59.88 and 50.82, correspondingly). Furthermore, all substituents are in syn-conformation along the Ge-Ge bonds (syn-syn conformation; the average torsion along $\mathrm{Ge}(2)-\mathrm{Ge}(1)$ is 1.38 and along $\mathrm{Ge}(2)-\mathrm{Ge}(3)$ is 10.96).

In the crystal 3 the solvated molecule of $n$-hexane is observed within wide channels formed by 3D packing (Fig. 2). There are no intermolecular contacts or interactions between the molecule of $n$-hexane and 3 . The molecule of $n$-hexane is fully ordered and any vibrations may be observed only in a low extent. Moreover, any attempts to remove the $n$-hexane molecule from the channels (by applying the high vacuum over $24 \mathrm{~h}$ or even by using a mild heating) were unsuccessful according to XRD, all characteristics of the crystal remained unchanged.. Therefore, donor-acceptor oligogermanes may form crystals suitable to fix inert moleculesin a fashion similar to MOFs.

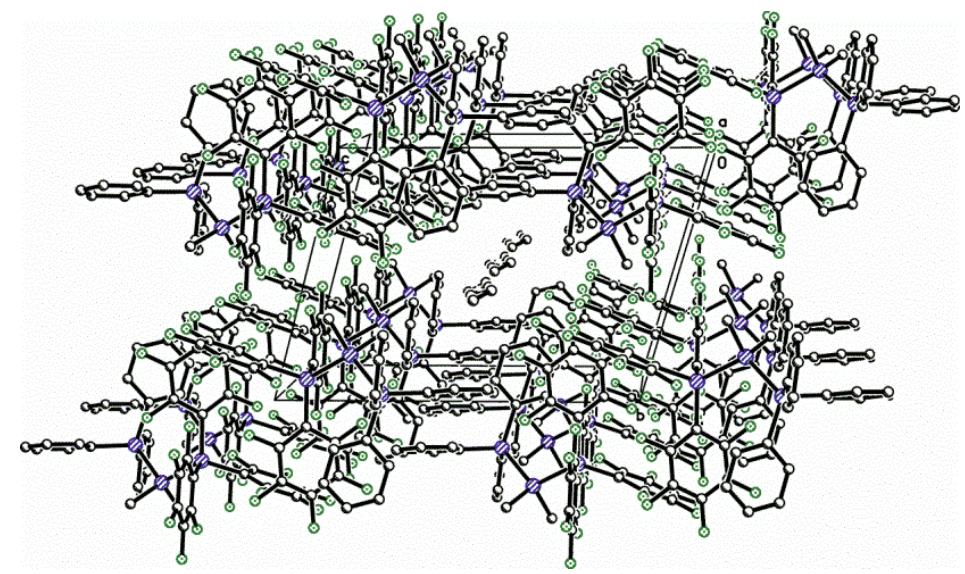

Fig. 2. Disposition of solvated molecule of $n$-hexane in the 3D structure of $\mathbf{3}$.

Crystals of molecular oligogermanes containing solvated molecules are known, but only with molecules of solvated benzene or toluene $\left(\mathrm{Ph}_{3} \mathrm{G}_{3} \mathrm{GePh}_{3} * 2 \mathrm{C}_{6} \mathrm{H}_{6}{ }^{[21]} \text {, ( } p \text {-Tol }\right)_{3} \mathrm{GeGe}$ (Tol-

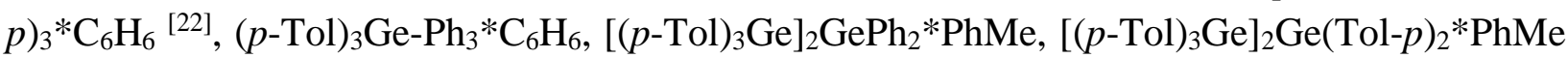
$\left.{ }^{[23]}, \mathrm{Ge}_{4} \mathrm{Ph}_{10} * 2 \mathrm{C}_{6} \mathrm{H}_{6}{ }^{[24]}\right)$.

To the best of our knowledge there are only 3 linear pentagermanes with known molecular solid state structure, $\mathrm{Ge}_{5} \mathrm{Ph}_{12}$ (at $295 \mathrm{~K}: d(\mathrm{Ge}-\mathrm{Ge})_{\mathrm{av}} 2.460(4)$ and $\mathrm{Ge}-\mathrm{Ge}-\mathrm{Ge}_{\mathrm{av}}$ $115.6(2)^{\circ}$; at $100 \mathrm{~K}: d(\mathrm{Ge}-\mathrm{Ge})_{\mathrm{av}} \quad 2.4502(6)$ and $\left.\mathrm{Ge}-\mathrm{Ge}-\mathrm{Ge}_{\mathrm{av}} \quad 115.52(2)^{\mathrm{o}} \quad[11 \mathrm{a}, \quad 25]\right)$, $\left(\mathrm{Me}_{3} \mathrm{Ge}\right)_{3} \mathrm{GeGeMe}_{2} \mathrm{Ge}\left(\mathrm{GeMe}_{3}\right)_{3}\left(d(\mathrm{Ge}-\mathrm{Ge})_{\mathrm{av}} 2.4425(9) \text { and } \mathrm{Ge}-\mathrm{Ge}-\mathrm{Ge}_{\mathrm{av}} 111.68(4)^{\circ}\right)^{[9 \mathrm{~b}]}$ and $(i-$ $\operatorname{Pr})_{3} \mathrm{Ge}\left[\mathrm{GePh}_{2}\right]_{3} \mathrm{Ge}(i-\mathrm{Pr})_{3}\left(d(\mathrm{Ge}-\mathrm{Ge})_{\mathrm{av}} 2.4710(8) \text { and } \mathrm{Ge}-\mathrm{Ge}-\mathrm{Ge}_{\mathrm{av}} 117.01(3)^{\mathrm{o}}\right)^{[26]}$. 


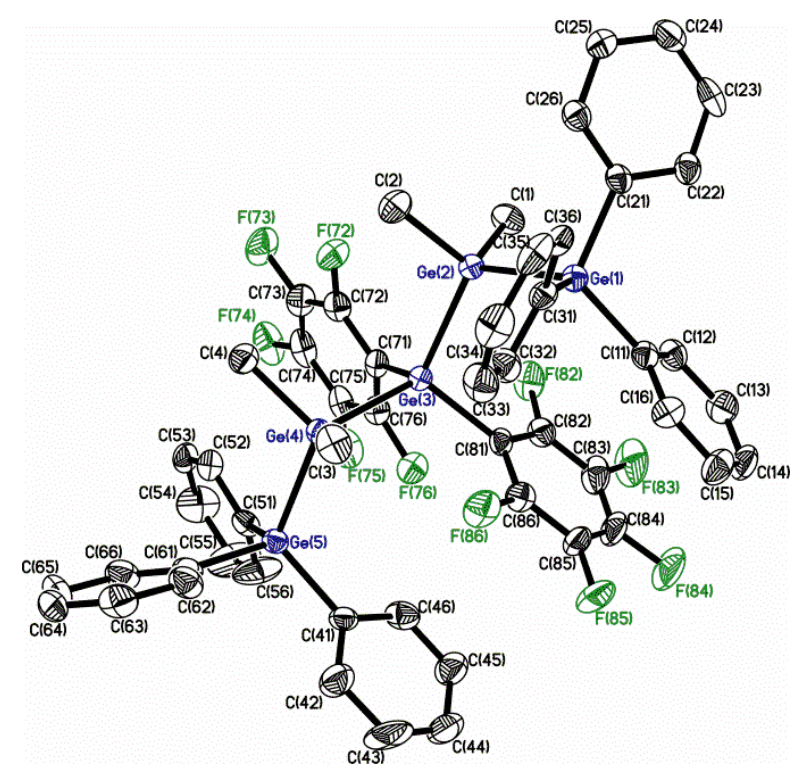

Fig. 3. Molecular structure of compound 4. Displacement ellipsoids are shown at 50\% probability level. Hydrogen atoms are omitted for clarity. Selected bond lengths $(\AA)$ and bond angles (deg): $\mathrm{Ge}(1)-\mathrm{Ge}(2)$ 2.4441(8), $\mathrm{Ge}(2)-\mathrm{Ge}(3)$ 2.4333(8), $\mathrm{Ge}(3)-\mathrm{Ge}(4)$ 2.4352(7), $\mathrm{Ge}(4)-$ $\mathrm{Ge}(5) \quad 2.4320(8), \quad \mathrm{Ge}(1)-\mathrm{C}_{\mathrm{av}}$ 1.953(5), Ge(2)- $\mathrm{C}_{\mathrm{av}}$ 1.960(5), $\mathrm{Ge}(3)-\mathrm{C}_{\mathrm{av}}$ 1.987(5), $\mathrm{Ge}(4)-$ $\mathrm{C}_{\mathrm{av}} 1.956(5), \mathrm{Ge}(5)-\mathrm{C}_{\mathrm{av}}$ 1.954(5); Ge(3)-Ge(2)-Ge(1) 115.50(3), Ge(2)-Ge(3)-Ge(4) 117.65(3), $\mathrm{Ge}(5)-\mathrm{Ge}(4)-\mathrm{Ge}(3)$ 115.04(3), C(31)-Ge(1)-Ge(2) 112.41(15), C(11)-Ge(1)-Ge(2) 114.45(15), $\mathrm{C}(21)-\mathrm{Ge}(1)-\mathrm{Ge}(2)$ 99.73(15), C(2)-Ge(2)-C(1) 110.2(2), C-Ge(2)-Ge(3)av 108.06(17), C-Ge(2)$\mathrm{Ge}(1)_{\mathrm{av}} 107.49(17), \mathrm{C}(81)-\mathrm{Ge}(3)-\mathrm{C}(71)$ 105.6(2), C-Ge(3)-Ge(2) av 108.63(15), C(81)-Ge(3)Ge(4) 115.65(15), C(71)-Ge(3)-Ge(4) 100.09(14), C(4)-Ge(4)-C(3) 105.0(2), C-Ge(4)-Ge(5)av 109.61(17), C(4)-Ge(4)-Ge(3) 103.54(16), C(3)-Ge(4)-Ge(3) 113.06(17), C-Ge(5)-C $\mathrm{C}_{\mathrm{av}}$ 108.7(2), $\mathrm{C}-\mathrm{Ge}(5)-\mathrm{Ge}(4)_{\mathrm{av}} 110.09(15)$.

Compound 4 crystallizes in a triclinic P-1 $(Z=2)$ space group, without any symmetry element. All four Ge-Ge bonds have slightly different lengths, where the longest and shortest ones are observed for the same groups at the ends of the molecule (Ge(1)-Ge(2) and Ge(4)$\mathrm{Ge}(5)$, respectively); the average value is $2.4362(8) \AA$. This bond length is shorter than the one known for other pentagermanes. This fact is explained by the electronic effects, due to a median substitution by electron withdrawing groups in the catenated Ge chain of $\mathbf{4}$. This effect is significant and different from in the end substitution in 3. Introduction of an electron withdrawing groups in the central part of the molecule results in a decrease of the Ge-Ge bond lengths.

As it was stated earlier for linear $\mathrm{Ge}_{5} \mathrm{Ph}_{12}$, the Ge-Ge bond length in the centre of the molecule is slightly longer than at the ends due to steric reasons $(2.4359(6)$ and $2.4397(6)$ for end and 2.4549(6) and 2.47001(6) for central) ${ }^{[25]}$, but in 4 this difference is almost negligeable. This could bebe explained by the presence of methyl groups instead of phenyl groups.

In 4, only four Ge atoms lie in one plane, while $\mathrm{Ge}(1)$ remains outside of this plane. Interestingly, the same situation has been observed earlier for aryl pentagermane $\mathrm{Ge}_{5} \mathrm{Ph}_{12}{ }^{[11 \mathrm{a}, 25]}$. Refering to the crystal structures for longer oligogermanes, namely $(i-\mathrm{Pr})_{3} \mathrm{Ge}\left[\mathrm{GePh}_{2}\right]_{4} \mathrm{Ge}(i-\mathrm{Pr})_{3}$ $[14,27]$, it is possible to state that for higher catenated Ge derivatives (more than 4 atoms in the 
chain) the end atoms are canted from the plane formed by the central atoms. Furthermore, in 4 in contrary from $\mathrm{Ge}_{5} \mathrm{Ph}_{12}$, the $\mathrm{Ge}-\mathrm{Ge}$ bond with $\mathrm{Ge}(1)$ atom out of plane is the longest one.

Comparing structural data for $\mathbf{3}$ and $\mathbf{4}$ it is evident that that the conjugation between the Ge atoms decreases the Ge-Ge bond length $\left(\mathrm{Ge}_{\mathrm{Me}}-\mathrm{Ge}_{\mathrm{Ph}} 2.4475(4)\right.$ vs. $\left.2.4320(8) \AA\right)$. The values of the Ge-Ge-Ge angles in $\mathbf{3}$ and $\mathbf{4}\left(115.780(14)\right.$ and average $\left.116.06(3)^{\circ}\right)$ are very similar.

In 4, the deviation of bond angles from the typical tetrahedral are observed $(\mathrm{C}(21)-\mathrm{Ge}(1)-$ $\mathrm{Ge}(2)$ 99.73(15), C(71)-Ge(3)-Ge(4) 100.09(14), C(4)-Ge(4)-Ge(3) 103.54(16)), possibly due to packing effects or to intermolecular interactions.Aryl groups (donor phenyl and acceptor perfluorophenyl) lie in parallel planes due to possible stacking, similar what was observed previously in $\mathrm{Ph}_{3} \mathrm{GeGe}\left(\mathrm{C}_{6} \mathrm{~F}_{5}\right)_{3}{ }^{[10]}$. The phenyl groups are in propeller-like conformation in relation to Ge-Ge bond, and the substituents at neighboring Ge atoms are in anti-syn ( $\mathrm{Ge}(1)$ $\mathrm{Ge}(3)$ ), gauche-gauche ( $\mathrm{Ge}(2)-\mathrm{Ge}(4))$ and anti-syn (Ge(3)-Ge(5)) conformations (torsions $\mathrm{C}(21)-$ $\mathrm{Ge}(1)-\mathrm{Ge}(2)-\mathrm{Ge}(3)$ 161.37; $\mathrm{Ge}(1)-\mathrm{Ge}(2)-\mathrm{Ge}(3)-\mathrm{Ge}(4)$ 89.80; $\mathrm{Ge}(2)-\mathrm{Ge}(3)-\mathrm{Ge}(4)-\mathrm{Ge}$ (5) 179.37; $\mathrm{Ge}(3)-\mathrm{Ge}(4)-\mathrm{Ge}(5)-\mathrm{C}(61)$ 176.18).

\subsection{Optical properties}

The optical properties (UV/vis absorbance and luminescence emission) of new donoracceptor ologogermanes $\mathbf{3}$ and $\mathbf{4}$ were investigated in details.

The UV/vis absorbance of $\mathbf{3}$ and is shown below (Fig. 4). In literature, only 5 known pentagermanes and 10 trigermanes have been reported to have been studied by UV/vis spectroscopy. The previously reported data are summarized in Table 1.

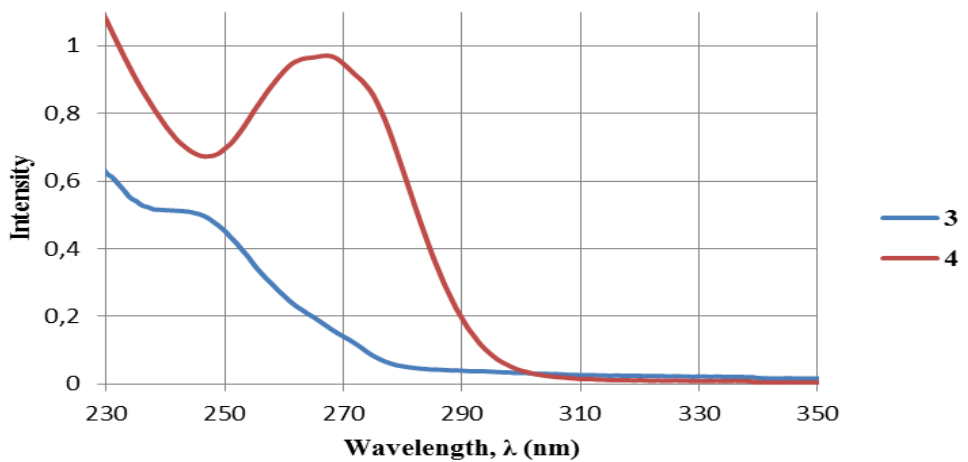

Fig. 4. UV/visible absorption spectra for compounds 3 and $4\left(\mathrm{CH}_{2} \mathrm{Cl}_{2}\right.$, rt).

Table 1. UV/vis absotption data for tri- and pentagermanes.

\begin{tabular}{|c|c|c|c|c|}
\hline compound & $\lambda, \mathrm{nm}$ & $\varepsilon * 10^{4}, \mathrm{M}^{-1} \mathrm{~cm}^{-1}$ & solvent & reference \\
\hline $\mathrm{Ph}_{3} \mathrm{GeGeMe}_{2} \mathrm{GePh}_{3}$ & 245 & 2.8 & cyclohexane & {$[8]$} \\
\hline $\mathrm{Ph}_{3} \mathrm{GeGeMePhGePh}_{3}$ & 250 & 3.6 & cyclohexane & [8] \\
\hline $\mathrm{Ph}_{3} \mathrm{GeGeEt}_{2} \mathrm{GePh}_{3}$ & 247 & 2.7 & cyclohexane & {$[8]$} \\
\hline $\mathrm{Ph}\left[\mathrm{GeEt}_{2}\right]_{3} \mathrm{Ph}$ & 241 & 2.0 & cyclohexane & {$[8]$} \\
\hline $\mathrm{Ph}_{3} \mathrm{GeGePh}_{2} \mathrm{GePh}_{3}$ & 250 & 2.6 & cyclohexane & {$[8]$} \\
\hline & 249 & 3.2 & $\mathrm{CH}_{2} \mathrm{Cl}_{2}$ & [24] \\
\hline
\end{tabular}




\begin{tabular}{|c|c|c|c|c|}
\hline $\mathrm{Me}_{3} \mathrm{GeGeMe}_{2} \mathrm{GeMe}_{3}$ & 218 & 0.9 & cyclohexane & [28] \\
\hline$\left[(p-\mathrm{Tol})_{3} \mathrm{Ge}\right]_{2} \mathrm{GeMe}_{2}$ & 251 & 4.0 & $\mathrm{CH}_{2} \mathrm{Cl}_{2}$ & [2] \\
\hline$\left[(p-\mathrm{Tol})_{3} \mathrm{Ge}\right]_{2} \mathrm{GePh}_{2}$ & 251 & & $\mathrm{CH}_{2} \mathrm{Cl}_{2}$ & [23] \\
\hline$\left[(p-\mathrm{Tol})_{3} \mathrm{Ge}\right]_{2} \mathrm{Ge}(p-\mathrm{Tol})_{3}$ & 253 & & $\mathrm{CH}_{2} \mathrm{Cl}_{2}$ & [23] \\
\hline$(i-\mathrm{Pr})_{3} \mathrm{Ge}\left[\mathrm{GePh}_{2}\right] \mathrm{Ge}(i-\mathrm{Pr})_{3}$ & 242 & 2.1 & $\mathrm{CH}_{2} \mathrm{Cl}_{2}$ & [26] \\
\hline$\left[(p-\mathrm{Tol})_{3} \mathrm{Ge}\right]_{2} \mathrm{Ge}\left(\mathrm{C}_{6} \mathrm{~F}_{5}\right)_{2}$ & 258 & 1.4 & $\mathrm{CH}_{2} \mathrm{Cl}_{2}$ & {$[10]$} \\
\hline$\left(p-\mathrm{F}_{3} \mathrm{CC}_{6} \mathrm{H}_{4}\right)_{3} \mathrm{Ge}-\mathrm{Ge}\left(\mathrm{C}_{6} \mathrm{~F}_{5}\right)_{2}-\mathrm{Ge}\left(\mathrm{C}_{6} \mathrm{H}_{4} \mathrm{CF}_{3}-p\right)_{3}$ & 264 & 2.4 & $\mathrm{CH}_{2} \mathrm{Cl}_{2}$ & [13] \\
\hline $\mathrm{Ph}_{3} \mathrm{GeGeMe}_{2} \mathrm{Ge}\left(\mathrm{C}_{6} \mathrm{~F}_{5}\right)_{3}(\mathbf{3})$ & 246 & 2.1 & $\mathrm{CH}_{2} \mathrm{Cl}_{2}$ & this work \\
\hline $\mathrm{Ph}\left[\mathrm{GeEt}_{2}\right]_{5} \mathrm{Ph}$ & 256 & 3.2 & cyclohexane & {$[8]$} \\
\hline $\mathrm{Ph}_{3} \mathrm{Ge}\left[\mathrm{GeEt}_{2}\right]_{3} \mathrm{GePh}_{3}$ & 269 & 3.9 & cyclohexane & [8] \\
\hline $\mathrm{Me}_{12} \mathrm{Ge}_{5}$ & 246 & 2.1 & cyclohexane & [28] \\
\hline \multirow[t]{2}{*}{$\mathrm{Ph}_{12} \mathrm{Ge}_{5}$} & 293 & 6.3 & $\mathrm{CH}_{2} \mathrm{Cl}_{2}$ & [11a] \\
\hline & 295 & 4.5 & $\mathrm{CH}_{2} \mathrm{Cl}_{2}$ & [25] \\
\hline$(i-\mathrm{Pr})_{3} \mathrm{Ge}[\mathrm{GePh}]_{3} \mathrm{Ge}(i-\mathrm{Pr})_{3}$ & 300 & 5.7 & $\mathrm{CH}_{2} \mathrm{Cl}_{2}$ & [26] \\
\hline$\left[\mathrm{Ph}_{3} \mathrm{GeGeMe}_{2}\right]_{2} \mathrm{Ge}\left(\mathrm{C}_{6} \mathrm{~F}_{5}\right)_{2}(\mathbf{4})$ & 267 & 4.5 & $\mathrm{CH}_{2} \mathrm{Cl}_{2}$ & this work \\
\hline
\end{tabular}

The main absorption in alkyl substituted oligogermanes is due to a $\sigma-\sigma^{*}$ transition where HOMO and LUMO are generally localized within the M-M bond [10], the nature of the substituent strongly impact on the energy level and disposition of these orbitals. Introduction of aryl groups moves the LUMO toward the Ar substituent, making the transitions to LUMO-1 etc. more preferable.

Table 1 shows that the change of the nature of the substituent in the central part of the molecule (insertion of aryl group) has a more significant red shift than when the groups at the end of the molecule are changed. Insertion of electron withdrawing $\mathrm{C}_{6} \mathrm{~F}_{5}$ groups at the end (in 3) or at median positions of Ge chain (in 4) has an similar effect to what we reported before ${ }^{[10]}$, i.e. weak bathochromic shift. Thus, in this case the degree of HOMO stabilization is less than the degree of LUMO destabilization. Furthermore, modification of substituent on the median part of the molecule leads to a stronger bathochromic shift in comparison with the end type.

When comparing the absorption of $\mathbf{3}$ with the one of $\mathbf{4}$ it is evident that the elongation of the Ge chain resulted in a bathochromic shift and in the coefficient of extinction also increased.

The luminescence properties of the compounds $\mathbf{3}$ and $\mathbf{4}$ in solid state and in solution have been also studied (Figs. 5, 6). The compounds show broad luminescence in both states. ItTothe best of our knowledge, in only few examples of investigation of catenated germanium compounds (including molecular and polymeric ones) as luminescent materials have been reported previously in the literature (see Table 2). 
Table 2. Luminescence emission data for the catenated germanium compounds

\begin{tabular}{|c|c|c|c|c|c|c|c|}
\hline \multirow[t]{2}{*}{ type } & \multirow[t]{2}{*}{ compound } & \multicolumn{2}{|c|}{ Solid state } & \multicolumn{3}{|c|}{ Solution $^{\mathrm{a}}$} & \multirow[t]{2}{*}{ reference } \\
\hline & & $\lambda_{\mathrm{em}}, \mathrm{nm}^{\mathrm{b}}$ & $\begin{array}{c}\text { Stokes shift, } \\
\mathrm{nm}\end{array}$ & $\lambda_{\mathrm{em}}(\mathrm{nm})$ & $\begin{array}{c}\text { Stokes shift, } \\
\mathrm{nm}\end{array}$ & $\begin{array}{c}\Phi_{\mathrm{f}} \\
(\%)^{\mathrm{c}}\end{array}$ & \\
\hline polymer & {$\left[\left(\mathrm{Me}_{3} \mathrm{SiOC}_{6} \mathrm{H}_{4}-p\right) \mathrm{MeGe}\right]_{\mathrm{n}}$} & 367 (film) & 35 & $\begin{array}{c}369(332, \\
\text { THF) }\end{array}$ & 39 & - & [29] \\
\hline \multirow[t]{10}{*}{ molecular } & $(p-\mathrm{Tol})_{3} \mathrm{GeGeMe}_{3}$ & $\begin{array}{c}357,373,393 \\
(300)\end{array}$ & $125,141,161$ & $286(270)$ & 54 & 3.27 & {$[18 c]$} \\
\hline & $(p-\mathrm{Tol})_{3} \mathrm{GeGeMe}{ }_{2} \mathrm{Ge}(p-\mathrm{Tol})_{3}$ & $438(380)$ & 187 & $338(285)$ & 87 & 1.85 & [2] \\
\hline & $\mathrm{Ph}_{3} \mathrm{Ge}-\mathrm{Ge}\left(\mathrm{C}_{6} \mathrm{~F}_{5}\right)_{3}$ & $373(270)$ & 147 & $377(265)$ & 151 & 12.50 & [2] \\
\hline & {$\left[\left(p-\mathrm{F}_{3} \mathrm{CC}_{6} \mathrm{H}_{4}\right)_{3} \mathrm{Ge}\right]_{2} \mathrm{Ge}\left(\mathrm{C}_{6} \mathrm{~F}_{5}\right)_{2}$} & $476(320)$ & 212 & $376(290)$ & 112 & 12.36 & [13] \\
\hline & $(i-\mathrm{Pr})_{3} \mathrm{Ge}\left[\mathrm{GePh}_{2}\right]_{4} \mathrm{Ge}(i-\mathrm{Pr})_{3}$ & - & - & $370(312)$ & 60 & - & [14] \\
\hline & $(i-\mathrm{Pr})_{3} \mathrm{Ge}\left[\mathrm{GePh}_{2}\right]_{3} \mathrm{Ge}(i-\mathrm{Pr})_{3}$ & - & - & $380(302)$ & 80 & - & [26] \\
\hline & $\mathrm{Ph}_{3} \mathrm{GeGeMe}_{2} \mathrm{Ge}\left(\mathrm{C}_{6} \mathrm{~F}_{5}\right)_{3}(\mathbf{3})$ & $379(325)$ & 133 & $351(290)$ & 107 & 5.45 & this work \\
\hline & & $373(270)$ & 127 & & & & \\
\hline & {$\left[\mathrm{Ph}_{3} \mathrm{GeGeMe}_{2}\right]_{2} \mathrm{Ge}\left(\mathrm{C}_{6} \mathrm{~F}_{5}\right)_{2}$} & $382(345)$ & 115 & $350(295)$ & 84 & 2.11 & this work \\
\hline & & $400(345)$ & 133 & & & & \\
\hline
\end{tabular}

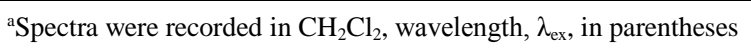

${ }^{\mathrm{b}}$ Excitation wavelength, $\lambda_{\mathrm{ex}}$, in parentheses

${ }^{\mathrm{c} Q u a n t u m}$ yield

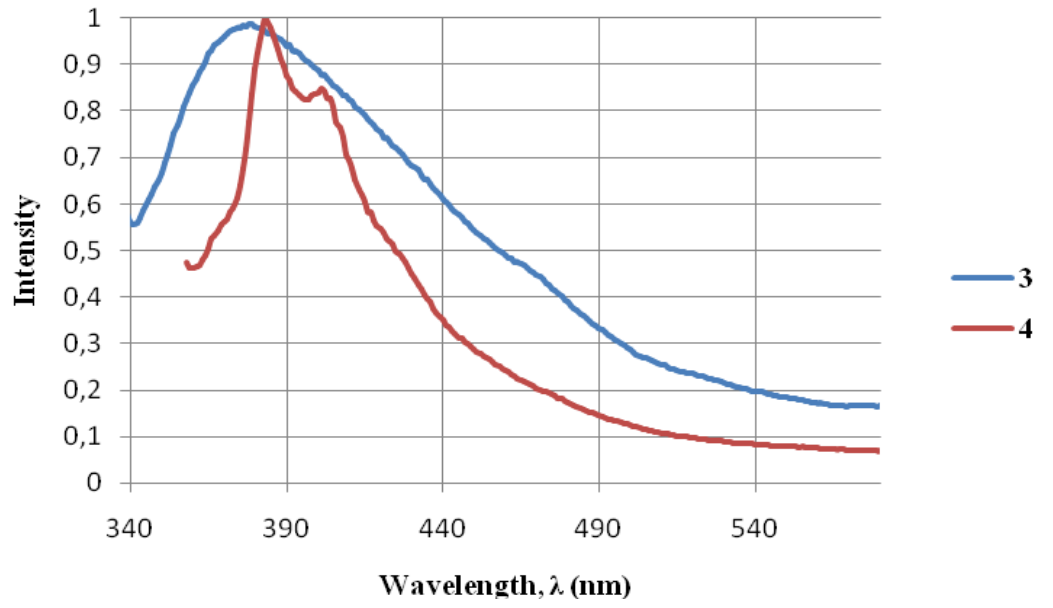

Fig. 5. Luminescence emission spectra for $\mathbf{3}$ and $\mathbf{4}$ in the solid state at room temperature.

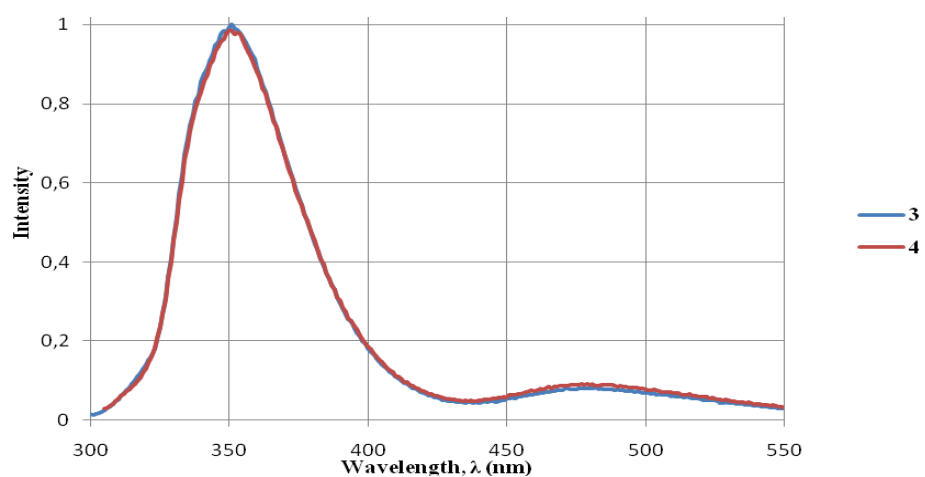

Fig. 6. Luminescence emission spectra for 3 and $\mathbf{4}$ in solution $\left(\mathrm{CH}_{2} \mathrm{Cl}_{2}\right.$, room temperature). 
In their solide state, $\mathbf{3}$ and $\mathbf{4}$ show an emission is shifted more toward the red than in solution, this may be explained by higher order in the condensed phase.

The spectra of $\mathbf{3}$ and $\mathbf{4}$ in solution are very similar due to common structural characteristics. In this case, the efficiency of the emission is low and the quantum yield is less than $6 \%$.

That simple elongation of the Ge chain has not significant impact on the expected red shift. Apparently, the coplanar trans-disposition of the Ge atoms in the chain plays a critical role for efficiency of the luminescence (high Stokes shift and quantum yield) as well as the electronic nature of the substituents, which strongly effect the HOMO/LUMO levels of the fundamental and excited states. Further investigation in this field will be performed in the near future.

\subsection{Electrochemical behavior}

The redox properties of compounds $\mathbf{3}$ and $\mathbf{4}$ were studied by the mean of cyclic voltammetry (CV) (Fig. 7; Fig. S11, Supporting Information). The electrochemical data for known tri- and pentagermanes are shown in Table 3.

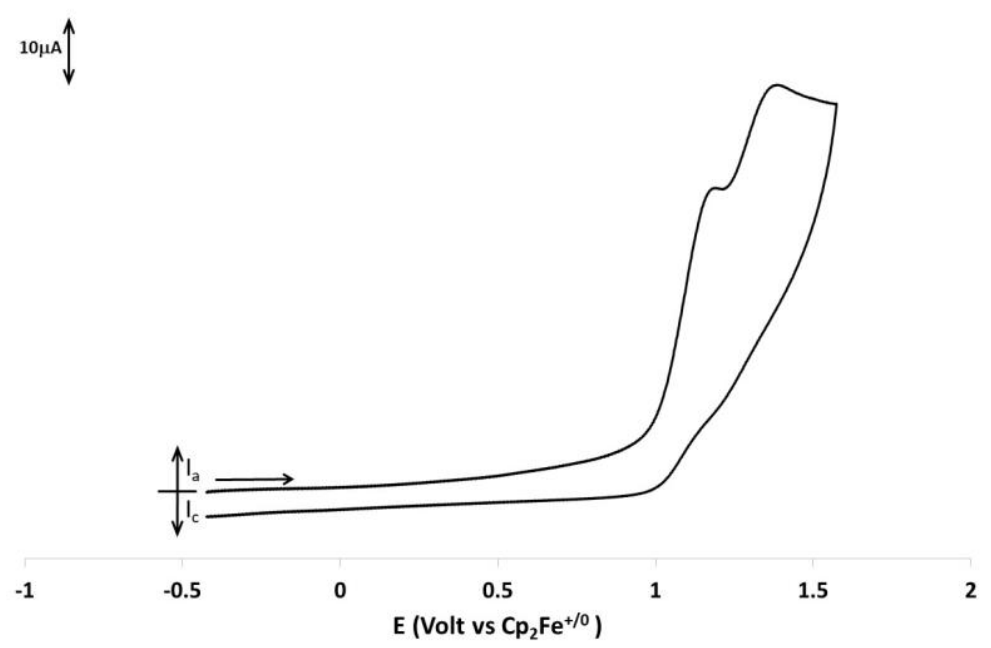

Fig. 7. Cyclic voltammogram of $1 \mathrm{mM}\left[\mathrm{Ph}_{3} \mathrm{GeGeMe}_{2}\right] \mathrm{Ge}\left(\mathrm{C}_{6} \mathrm{~F}_{5}\right)_{2}(4)$ in dichloromethane - $\left[\mathrm{NBu}_{4}\right]\left[\mathrm{PF}_{6}\right]$ solution. Sweeping rate $200 \mathrm{mV} / \mathrm{s}$ at room temperature.

Table 3. Electrochemical data for tri- and pentagermanes by $\mathrm{CV}$.

\begin{tabular}{|c|c|c|c|c|}
\hline compound & $\mathrm{E}, \mathrm{V}^{\mathrm{a}}$ & standard & conditions & reference \\
\hline $\mathrm{Me}_{3} \mathrm{GeGeMe}_{2} \mathrm{GeMe}_{3}^{\mathrm{b}}$ & $0.93(1.42)^{\mathrm{c}}$ & $\mathrm{Fc}^{+} / \mathrm{Fc}$ & $\mathrm{MeCN}, 0.1 \mathrm{M}$ TBAP & {$[28]$} \\
\hline$\left(\mathrm{EtOCH}_{2} \mathrm{CH}_{2}\right) \mathrm{Et}_{2} \mathrm{GeGePh}_{2} \mathrm{GeEt}_{2}\left(\mathrm{CH}_{2} \mathrm{CH}_{2} \mathrm{OEt}\right)$ & 1.577 & $\mathrm{Ag} / \mathrm{AgCl}$ & $\mathrm{MeCN}, 1.0 \mathrm{M}\left[\mathrm{Bu}_{4} \mathrm{~N}\right]\left[\mathrm{PF}_{6}\right]$ & [30] \\
\hline$\left(\mathrm{EtOCH}_{2} \mathrm{CH}_{2}\right) \mathrm{Bu}_{2} \mathrm{GeGePh}_{2} \mathrm{GeBu}_{2}\left(\mathrm{CH}_{2} \mathrm{CH}_{2} \mathrm{OEt}\right)$ & 1.500 & $\mathrm{Ag} / \mathrm{AgCl}$ & $\mathrm{MeCN}, 1.0 \mathrm{M}\left[\mathrm{Bu}_{4} \mathrm{~N}\right]\left[\mathrm{PF}_{6}\right]$ & [30] \\
\hline$\left(\mathrm{EtOCH}_{2} \mathrm{CH}_{2}\right) \mathrm{Ph}_{2} \mathrm{GeGePh}_{2} \mathrm{GePh}_{2}\left(\mathrm{CH}_{2} \mathrm{CH}_{2} \mathrm{OEt}\right)$ & 1.609 & $\mathrm{Ag} / \mathrm{AgCl}$ & $\mathrm{MeCN}, 1.0 \mathrm{M}\left[\mathrm{Bu}_{4} \mathrm{~N}\right]\left[\mathrm{PF}_{6}\right]$ & [30] \\
\hline $\mathrm{Ph}_{3} \mathrm{Ge}\left[\mathrm{GeBu}_{2}\right]_{2}\left(\mathrm{CH}_{2} \mathrm{CH}_{2} \mathrm{OEt}\right)$ & 1.546 & $\mathrm{Ag} / \mathrm{AgCl}$ & $\mathrm{MeCN}, 1.0 \mathrm{M}\left[\mathrm{Bu}_{4} \mathrm{~N}\right]\left[\mathrm{PF}_{6}\right]$ & [30] \\
\hline $\mathrm{Ph}_{3} \mathrm{GeGeBu}_{2} \mathrm{GePh}_{2}\left(\mathrm{CH}_{2} \mathrm{CH}_{2} \mathrm{OEt}\right)$ & 1.525 & $\mathrm{Ag} / \mathrm{AgCl}$ & $\mathrm{MeCN}, 1.0 \mathrm{M}\left[\mathrm{Bu}_{4} \mathrm{~N}\right]\left[\mathrm{PF}_{6}\right]$ & [30] \\
\hline $\mathrm{Ph}_{3} \mathrm{GeGePh}_{2} \mathrm{GePh}_{3}$ & $1.696,2.052$ & $\mathrm{Ag} / \mathrm{AgCl}$ & $\mathrm{CH}_{2} \mathrm{Cl}_{2}, 0.1 \mathrm{M}\left[\mathrm{Bu}_{4} \mathrm{~N}\right]\left[\mathrm{PF}_{6}\right]$ & [23] \\
\hline$\left[(p-\mathrm{Tol})_{3} \mathrm{Ge}\right]_{2} \mathrm{GePh}_{2}$ & $1.498,1.860$ & $\mathrm{Ag} / \mathrm{AgCl}$ & $\mathrm{CH}_{2} \mathrm{Cl}_{2}, 0.1 \mathrm{M}\left[\mathrm{Bu}_{4} \mathrm{~N}\right]\left[\mathrm{PF}_{6}\right]$ & [23] \\
\hline
\end{tabular}




\begin{tabular}{|c|c|c|c|c|}
\hline$\left[(p-\mathrm{Tol})_{3} \mathrm{Ge}\right]_{2} \mathrm{Ge}(p-\mathrm{Tol})_{3}$ & $1.542,1.865$ & $\mathrm{Ag} / \mathrm{AgCl}$ & $\mathrm{CH}_{2} \mathrm{Cl}_{2}, 0.1 \mathrm{M}\left[\mathrm{Bu}_{4} \mathrm{~N}\right]\left[\mathrm{PF}_{6}\right]$ & [23] \\
\hline$(i \text {-Pr })_{3} \mathrm{Ge}\left[\mathrm{GePh}_{2}\right] \mathrm{Ge}(i-\mathrm{Pr})_{3}$ & 1.555 & $\mathrm{Ag} / \mathrm{AgCl}$ & $\mathrm{CH}_{2} \mathrm{Cl}_{2}, 0.1 \mathrm{M}\left[\mathrm{Bu}_{4} \mathrm{~N}\right]\left[\mathrm{PF}_{6}\right]$ & [26] \\
\hline$(n-\mathrm{Bu})_{3} \mathrm{GeGePh}_{2} \mathrm{Ge}(n-\mathrm{Bu})_{3}$ & 1.540 & $\mathrm{Ag} / \mathrm{AgCl}$ & $\mathrm{CH}_{2} \mathrm{Cl}_{2}, 0.1 \mathrm{M}\left[\mathrm{Bu}_{4} \mathrm{~N}\right]\left[\mathrm{PF}_{6}\right]$ & [16] \\
\hline$\left(p-\mathrm{F}_{3} \mathrm{CC}_{6} \mathrm{H}_{4}\right)_{3} \mathrm{Ge}-\mathrm{Ge}\left(\mathrm{C}_{6} \mathrm{~F}_{5}\right)_{2}-\mathrm{Ge}\left(\mathrm{C}_{6} \mathrm{H}_{4} \mathrm{CF}_{3}-p\right)_{3}$ & 1.27 (1.76), $1.63(2.12)$ & $\mathrm{Fc}^{+} / \mathrm{Fc}$ & $\mathrm{CH}_{2} \mathrm{Cl}_{2}, 0.05 \mathrm{M}\left[\mathrm{NBu}_{4}\right]\left[\mathrm{B}\left(\mathrm{C}_{6} \mathrm{~F}_{5}\right)_{4}\right]$ & [13] \\
\hline $\mathrm{Ph}_{3} \mathrm{GeGeMe}_{2} \mathrm{Ge}\left(\mathrm{C}_{6} \mathrm{~F}_{5}\right)_{3}(\mathbf{3})$ & $1.53(2.02)$ & $\mathrm{Fc}^{+} / \mathrm{Fc}$ & $\mathrm{CH}_{2} \mathrm{Cl}_{2},\left[\mathrm{NBu}_{4}\right]\left[\mathrm{PF}_{6}\right]$ & this work \\
\hline $\mathrm{Me}_{12} \mathrm{Ge}_{5}^{\mathrm{d}}$ & $0.61(1.10)^{\mathrm{c}}$ & $\mathrm{Fc}^{+} / \mathrm{Fc}$ & MeCN, 0.1 M TBAP & [28] \\
\hline $\mathrm{Ph}_{3} \mathrm{Ge}\left[\mathrm{GePh}_{2}\right]_{3} \mathrm{GePh}_{3}$ & $1.385,1.605,1.777,1.998$ & $\mathrm{Ag} / \mathrm{AgCl}$ & $\mathrm{CH}_{2} \mathrm{Cl}_{2}, 0.1 \mathrm{M}\left[\mathrm{Bu}_{4} \mathrm{~N}\right]\left[\mathrm{PF}_{6}\right]$ & [25] \\
\hline$(i-\mathrm{Pr})_{3} \mathrm{Ge}\left[\mathrm{GePh}_{2}\right]_{3} \mathrm{Ge}(i-\mathrm{Pr})_{3}$ & $1.560,1.695,1.875,2.095$ & $\mathrm{Ag} / \mathrm{AgCl}$ & $\mathrm{CH}_{2} \mathrm{Cl}_{2}, 0.1 \mathrm{M}\left[\mathrm{Bu}_{4} \mathrm{~N}\right]\left[\mathrm{PF}_{6}\right]$ & [26] \\
\hline$\left[\mathrm{Ph}_{3} \mathrm{GeGeMe}_{2}\right]_{2} \mathrm{Ge}\left(\mathrm{C}_{6} \mathrm{~F}_{5}\right)_{2}(\mathbf{4})$ & $1.18(1.67), 1.38(1.87)$ & $\mathrm{Fc}^{+} / \mathrm{Fc}$ & $\mathrm{CH}_{2} \mathrm{Cl}_{2},\left[\mathrm{NBu}_{4}\right]\left[\mathrm{PF}_{6}\right]$ & this work \\
\hline $\begin{array}{l}{ }^{a} \text { Values in relation to } \mathrm{Ag} / \mathrm{AgCl} \text { are give } \\
\text { b } \text { Reduction process is also observed at } \\
{ }^{\mathrm{c}} \text { Half peak potentials } \\
{ }^{\mathrm{d}} \text { Reduction process is also observed at }\end{array}$ & $\begin{array}{l}\text { in the parentheses } \\
2=-0.56 \mathrm{~V} \\
2=-0.48 \mathrm{~V}\end{array}$ & & & \\
\hline
\end{tabular}

The electrochemical data about oligogermanes containing alkyl and aryl groups are very rare, so this investigation makes a significant contribution to this field. As it was reported before, only one oxidation process is observed for fully alkylated oligogermanes. On contrary, in fully arylated oligogermanes, an electronic interaction between $\pi$ - and $\sigma$-groups ${ }^{[10]}$ is observed, what results in a stabilization of the HOMO and in a decrease of the oxidation potential. In this case Weinert et al. have previously established that aryl substituted oligogermanes with $\mathrm{n} G e$ atoms in their chain, are characterized by $\mathrm{n}-1$ irreversible oxidation processes ${ }^{[23]}$. In the case of oligogermanes containing aryl and alkyl groups the situation is less predictable (see Table 3).

Compound 3 showed only one oxidation at $1.53 \mathrm{~V} v s . \mathrm{Fc}^{+} / \mathrm{Fc}(2.02 \mathrm{~V} v s$. $\mathrm{Ag} / \mathrm{AgCl})$. It is evident that if alkyl groups are present in oligogermanes, the oxidation potential will higher than for their aryl analogs and in this case it is possible to observe only one wave ${ }^{[28]}$. Elongation of the $\mathrm{Ge}$ chain in 3 in comparison with donor-acceptor digermane $\mathrm{Ph}_{3} \mathrm{GeGe}\left(\mathrm{C}_{6} \mathrm{~F}_{5}\right)_{3}{ }^{[2]}$ decreases the first oxidation potential $(1.53$ vs. $1.62 \mathrm{~V})$. Compound $\mathbf{4}$ has only two oxidation peaks at $\mathrm{E}_{\mathrm{pa}}=$ 1.18 and $1.38 \mathrm{~V} v$ s. $\mathrm{Fc}^{+} / \mathrm{Fc}(1.67$ and $1.87 \mathrm{~V} v$ s. $\mathrm{Ag} / \mathrm{AgCl})$. In this case, the elongation of the $\mathrm{Ge}$ chain significantly stabilizes the HOMO even in the presence of electron withdrawing substituents. In general, introduction of alkyl or of an electron withdrawing groups into the oligogermane chain stabilizes the HOMO of the oligogermane (as observed earlier for donoracceptor and for oligogermanes fully substituted by acceptor groups ${ }^{[2,13]}$ ) and hence increases the values of the oxidation potential.

Although more electrochemical mechanistic investigations needs to be carried out, one possible mechanism for the oxidation of oligogermanes is depicted in Scheme 4. In this mechanism, the first oxidation occurs on the $\sigma$-bonding orbital between the $\mathrm{M}$ atoms ${ }^{[31]}$, and the resulting highly unstable transient cation-radical decomposes rapidly. Among the two main pathways of decomposition, the extrusion of germylene with formation of a novel cation-radical or the rupture of Ge-Ge bond with formation of a cation and a radical ${ }^{[10]}$, the latest one seems the more plausible.. The cation and radical formed would then further react. Nevertheless, it is 
impossible to completely rule out the presence of additional oxidaitons at higher potentials that would be located outside of the electrochemical window.

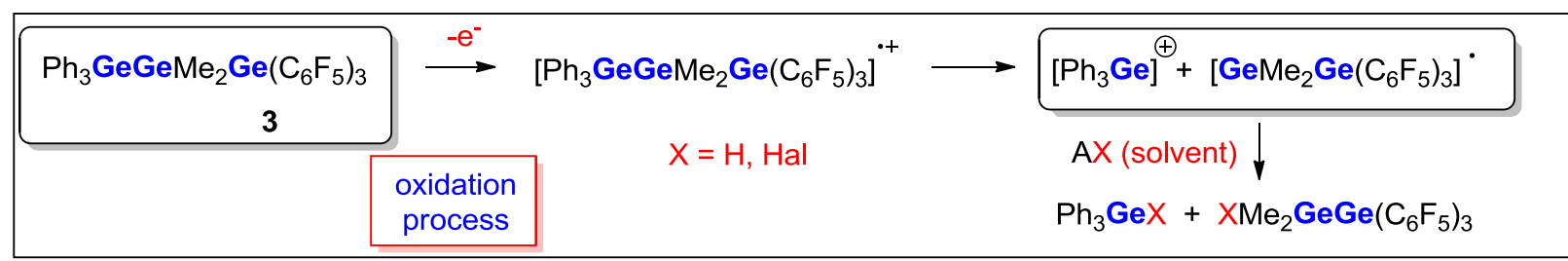

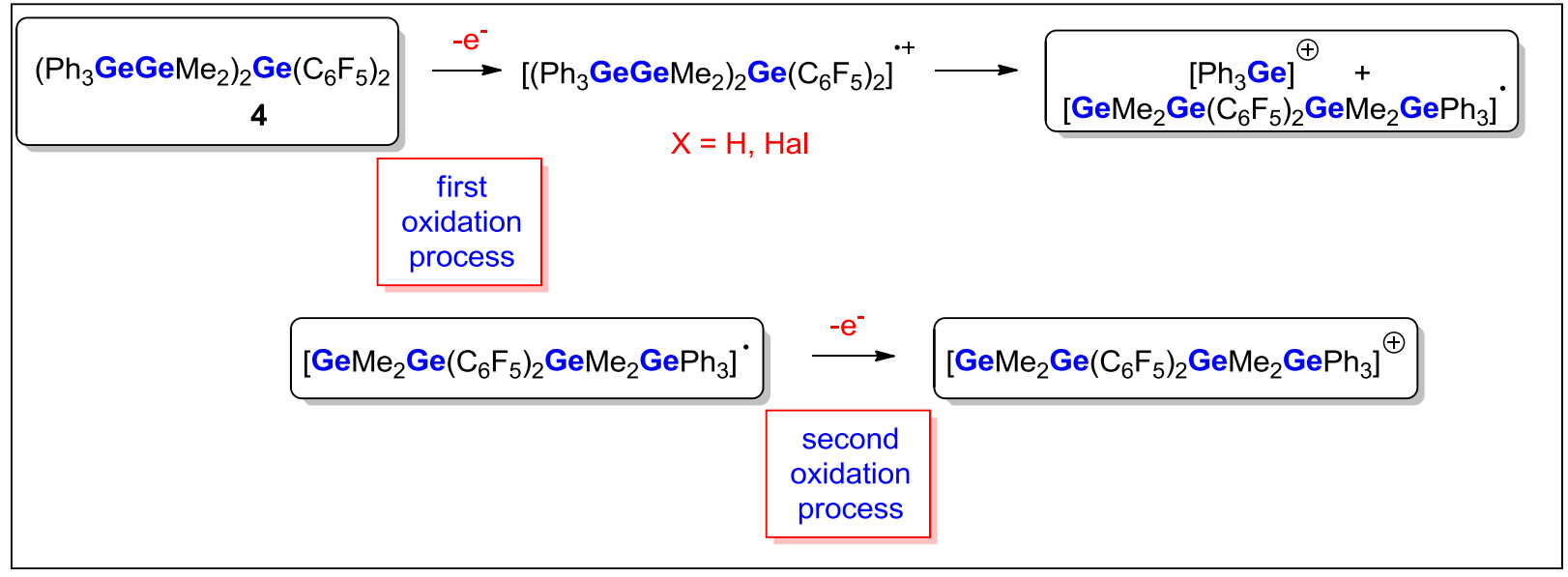

Scheme 4. Mechanism of irreversible oxidation of catenated germanes.

This mechanism may be applicable to the oxidation of alkyl substituted oligogermanes,. [28] [26] In the case of aryl substituted oligogermanes, the intermediate cation and radical should be sufficiently stable to form catenated derivative that could undergo subsequent oxidations as observed by Weinert et al. ${ }^{[23]}$

The structure of oligogermanes (especially the nature of the substituents) strongly impacts on the oxidation potential and pathway.

\section{Conclusions}

Linear oligogermanium amide 2, $\mathrm{Ph}_{3} \mathrm{GeGeMe}_{2} \mathrm{NMe}_{2}$, was obtained and used in an hydrogermolysis reaction with $\mathrm{HGe}\left(\mathrm{C}_{6} \mathrm{~F}_{5}\right)_{3}$ and $\mathrm{H}_{2} \mathrm{Ge}\left(\mathrm{C}_{6} \mathrm{~F}_{5}\right)_{2}$ by heating in $n$-hexane for the synthesis of the donor-acceptor germanes 3 and $\mathbf{4}$. It has been experimentaly shown that the physical properties of catenated germanes depend on the type of substitution by withdrawing groups. Median insertion significantly has a greater effect than a substitution located at the end of the chain. The conformation of the molecule is determined by the intramolecular contacts between donor (phenyl) and acceptor (perfluorophenyl) groups, resulting in an eclipsed conformation along the Ge-Ge bonds. Nonpolar oligogermanes in a crystal could form wide channels in which organic molecules may be trapped. The number of oxidation waves in $\mathrm{CV}$ investigations strongly depends on the electronic nature of the substituent and on the number of Ge atoms within the molecule. As expected, electron withdrawing groups decrease the oxidation potential of the molecule, while longer Ge chain increases that potential. Oligogermanes have wide emission spectra, in solid state, their luminescence (Stokes shift) is snigificantly more shifted toward the red than when they are in solution. 


\section{Experimental Part}

\subsection{General Remarks}

All reactions were carried out in protective atmosphere using standard Schlenk techniques. $\mathrm{GeCl}_{4}$ (Aldrich) was distilled prior to use. $n$-BuLi (Aldrich) was used as supplied. Solvents were dried using standard procedures (ether was stored over $\mathrm{KOH}$ and then distilled over $\mathrm{Na}$ /benzophenone, $n$-hexane was distilled over $\mathrm{Na}$ ).

${ }^{1} \mathrm{H}$ NMR (400.130 MHz), ${ }^{13} \mathrm{C}$ NMR (100.613 MHz) and ${ }^{19} \mathrm{~F}$ (376.498 MHz) spectra were recorded on Bruker 400 or Agilent 400MR spectrometers at $298 \mathrm{~K}$. Chemical shifts are given in ppm relative to internal reference $\mathrm{Me}_{4} \mathrm{Si}\left({ }^{1} \mathrm{H}\right.$ and ${ }^{13} \mathrm{C}$ NMR spectra) or external reference $\mathrm{CFCl}_{3}$ $\left({ }^{19} \mathrm{~F}\right.$ spectra). Elemental analyses were carried out by the Microanalytical Laboratory of the Chemistry Department of the Moscow State University using Heraeus Vario Elementar instrument. UV/visible spectra were recorded using a double-beam spectrophotometer Evolution 300 «Thermo Scientific» using a $1.00 \mathrm{~cm}$ cuvette.

Electrochemical measurements were carried out using an Autolab 302N potentiostat interfaced through Nova 2.0 software to a personal computer. Electrochemical measurements were performed in a glovebox under oxygen levels of less than $5 \mathrm{ppm}$ using solvent that had been purified by passing through an alumina-based purification system. Diamond-polished glassy carbon electrodes of $3 \mathrm{~mm}$ diameter were employed for cyclic voltammetry (CV) scans. CV data were evaluated using standard diagnostic criteria for diffusion control and for chemical and electrochemical reversibility. The experimental reference electrode was a silver wire coated with anodically deposited silver chloride and separated from the working solution by a fine glass frit. The electrochemical potentials in this paper are referenced to ferrocene/ferrocenium couple, as recommended elsewhere. ${ }^{38]}$ The ferrocene potential was obtained by its addition to the analyte solution. At an appropriate time in the experiment.

Known compounds, $\mathrm{Ph}_{3} \mathrm{GeCl}^{[18 \mathrm{a}]}, \mathrm{Me}_{2} \mathrm{GeCl}_{2}{ }^{[13]}, \mathrm{Me}_{2} \mathrm{Ge}\left(\mathrm{NMe}_{2}\right)_{2}{ }^{[13]},\left(\mathrm{C}_{6} \mathrm{~F}_{5}\right)_{3} \mathrm{GeH}^{[10]}$ and $\left(\mathrm{C}_{6} \mathrm{~F}_{5}\right)_{2} \mathrm{GeH}_{2}{ }^{[10]}$, were prepared according to published procedures. Improved protocols were used for the synthesis of $\mathrm{Ph}_{3} \mathrm{GeH}$.

\subsection{Synthesis of Starting Materials}

Synthesis of triphenylgermane. Improved procedure was applied [32]. At room temperature a solution of $\mathrm{Ph}_{3} \mathrm{GeCl}(5.48 \mathrm{~g}, 16.10 \mathrm{mmol})$ in ether $(40 \mathrm{ml})$ was added dropwise to the suspension of $\mathrm{LiAlH}_{4}(0.79 \mathrm{~g}, 30.93 \mathrm{~g})$ in ether $(40 \mathrm{ml})$. The mixture obtained was refluxed for $3 \mathrm{~h}$, then at room temperature $2 \mathrm{M} \mathrm{H}_{2} \mathrm{SO}_{4}(40 \mathrm{~mL})$ was added dropwise, organic phase was separated, aqueous layer was extracted with ether $(3 \times 20 \mathrm{~mL})$. Combined organic phases were dried over anhydrous $\mathrm{Na}_{2} \mathrm{SO}_{4}$, then solvent was removed under reduced pressure, and the residue was recrystallized from $n$-hexane. $\mathrm{Ph}_{3} \mathrm{GeH}(4.21 \mathrm{~g}, 86 \%)$ was isolated as a white powder, m.p. 42-43 ${ }^{\circ} \mathrm{C}$, m.p. ${ }^{[32 \mathrm{~b}]} 42{ }^{\circ} \mathrm{C} .{ }^{1} \mathrm{H} \mathrm{NMR}\left(\delta\right.$, ppm, $\left.\mathrm{CDCl}_{3}\right): 7.61-7.57$ (m, 6H, aromatic protons), 7.44$7.38(\mathrm{~m}, 9 \mathrm{H}$, aromatic protons $), 5.77(\mathrm{~s}, 1 \mathrm{H}, \mathrm{GeH}) \cdot{ }^{13} \mathrm{C} \mathrm{NMR}\left(\delta, \mathrm{ppm}, \mathrm{CDCl}_{3}\right): 135.68$ (quaternary aromatic carbon), 135.18, 128.36 ( $m$ - and $o-C H$ aromatic carbons), 129.14 ( $p-C H$ aromatic carbon). ${ }^{1} \mathrm{H}$ NMR $\left(\delta, \mathrm{ppm}, \mathrm{C}_{6} \mathrm{D}_{6}\right)$ : 7.54-7.49 (m, 6H, aromatic protons), 7.15-7.11 (m, $9 \mathrm{H}$, aromatic protons), $5.85(\mathrm{~s}, 1 \mathrm{H}, \mathrm{GeH}) .{ }^{13} \mathrm{C} \mathrm{NMR}\left(\delta, \mathrm{ppm}, \mathrm{C}_{6} \mathrm{D}_{6}\right): 135.83$ (quaternary aromatic carbon), 135.50, 128.67 ( $m$ - and $o-C H$ aromatic carbons), 129.37 ( $p-C H$ aromatic carbon).

$\left(\mathrm{N}, \mathrm{N}\right.$-Dimethylamino)chlorodimethylgermane, $\mathrm{Me}_{2} \mathrm{Ge}\left(\mathrm{NMe}_{2}\right) \mathrm{Cl} \quad(\mathbf{1})$. At $0^{\circ} \mathrm{C}$ $\mathrm{Me}_{2} \mathrm{GeCl}_{2}(0.87 \mathrm{ml}, 1.30 \mathrm{~g}, 7.50 \mathrm{mmol})$ was added slowly to the $\mathrm{Me}_{2} \mathrm{Ge}\left(\mathrm{NMe}_{2}\right)_{2}(1.43 \mathrm{~g}, 7.50$ mmol). Reaction mixture was stirred overnight, then all volatile materials were removed under 
reduced pressure. Compound $1(1.97 \mathrm{~g}, 72 \%)$ was obtained as a colorless oil after distillation, b.p. $121{ }^{\circ} \mathrm{C}$, b. p. $142\left(1013\right.$ mbar) ${ }^{[20 \mathrm{a}]}, 114{ }^{[20 \mathrm{~b}]} .{ }^{1} \mathrm{H}$ NMR $\left(\delta, \mathrm{ppm}, \mathrm{C}_{6} \mathrm{D}_{6}\right): 2.41$ (s, 6H, $\left.\mathrm{NMe}_{2}\right)$, $0.43\left(\mathrm{~s}, 6 \mathrm{H}, \mathrm{GeMe}_{2}\right) .1 \mathrm{H} \mathrm{NMR}$ specteum corresponds to literature data ${ }^{[20 \mathrm{a}]} .{ }^{13} \mathrm{C} \mathrm{NMR}(\delta, \mathrm{ppm}$, $\left.\mathrm{C}_{6} \mathrm{D}_{6}\right): 39.48\left(\mathrm{NMe}_{2}\right), 2.36\left(\mathrm{GeMe}_{2}\right)$.

Ph $_{3} \mathrm{GeGeMe}_{2} \mathrm{NMe}_{2}$ (2). a) Synthesis of Ph $\mathrm{h}_{3} \mathrm{GeLi}$ : At $-78^{\circ} \mathrm{C} n$-BuLi $(6.00 \mathrm{ml}, 2.5 \mathrm{M}$, $15.00 \mathrm{mmol})$ was added dropwise to the solution of $\mathrm{Ph}_{3} \mathrm{GeH}(4.57 \mathrm{~g}, 15.00 \mathrm{mmol})$ in ether (60 $\mathrm{ml}$ ). Then reaction mixture was heated slowly to room temperature and stirred for $3 \mathrm{~h}$. The solution of $\mathrm{Ph}_{3} \mathrm{GeLi}$ obtained in situ was used further without purification.

b) Synthesis of 2: At $-78^{\circ} \mathrm{C}$ the solution of $\mathrm{Ph}_{3} \mathrm{GeLi}$ in ether obtained as described above was added dropwise to the solution of compound 1 (2.73 g, $15 \mathrm{mmol})$ in ether $(20 \mathrm{ml})$. Reaction mixture was slowly warmed to room temperature and stirred overnight. Then all volatile materials were removed under reduced pressure, dissolved in $n$-hexane and filtered. Compound 2 $(5.54 \mathrm{~g}, 82 \%)$ was obtained as a white low melting glass after evaporation. ${ }^{1} \mathrm{H} \mathrm{NMR}(\delta, \mathrm{ppm}$, $\left.\mathrm{C}_{6} \mathrm{D}_{6}\right)$ : 7.67-7.61 (m, $6 \mathrm{H}$, aromatic protons), 7.23-7.15 (m, 9H, aromatic protons), $2.51(\mathrm{~s}, 6 \mathrm{H}$, $\left.\mathrm{NMe}_{2}\right), 0.48$ (s, 6H, GeMe 2$) .{ }^{13} \mathrm{C} \mathrm{NMR}\left(\delta, \mathrm{ppm}, \mathrm{C}_{6} \mathrm{D}_{6}\right): 138.59$ (quaternary aromatic carbon), 135.74, 128.70 ( $m$ - and $o-C H$ aromatic carbons), 128.92 ( $p-C \mathrm{H}$ aromatic carbon), $42.18\left(\mathrm{NMe}_{2}\right)$, -1.00 ( $\left.\mathrm{GeMe}_{2}\right)$. Anal. Calcd. for $\mathrm{C}_{22} \mathrm{H}_{27} \mathrm{Ge}_{2} \mathrm{~N}\left(\mathrm{M}_{\mathrm{w}}\right.$ 450.7365): C, 58.62; H, 6.04; N, 6.04. Found: C, 57.74; H, 5.73; N, 5.64.

\subsection{Synthesis of Donor-Acceptor Oligogermanes}

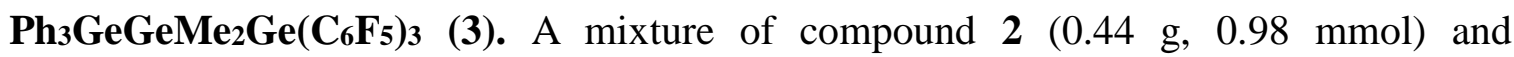
$\left(\mathrm{C}_{6} \mathrm{~F}_{5}\right)_{3} \mathrm{GeH}(0.56 \mathrm{~g}, 0.98 \mathrm{mmol})$ was dissolved in $n$-hexane $(20 \mathrm{ml})$. The solution obtained was frozen in liquid nitrogen, evacuated in high vacuum and then slowly warmed to room temperatire (three times). The mixture was heated on oil bath at $100^{\circ} \mathrm{C}$ for $84 \mathrm{~h}$. Then all volatile materials were removed under reduced pressure, the residue was extracted with $\mathrm{CH}_{2} \mathrm{Cl}_{2}(50 \mathrm{ml})$, evaporated and recrystallized from $n$-hexane. Compound $3(0.75 \mathrm{~g}, 78 \%)$ was obtained as a white powder, m.p. 163-164 ${ }^{\circ} \mathrm{C} .{ }^{1} \mathrm{H}$ NMR $\left(\delta, \mathrm{ppm}, \mathrm{CDCl}_{3}\right)$ : 7.37-7.27 (m, 15H, aromatic protons), 0.78 (s, $\left.6 \mathrm{H}, \mathrm{GeMe}_{2}\right) .{ }^{13} \mathrm{C} \mathrm{NMR}\left(\delta, \mathrm{ppm}, \mathrm{CDCl}_{3}\right): 135.72$ (quaternary aromatic carbon), 134.86, 128.33 ( $m$ - and $o-C H$ aromatic carbons), 129.06 ( $p$ - $C \mathrm{H}$ aromatic carbon), $-0.87\left(\mathrm{GeMe}_{2}\right)$. The signals of $\mathrm{C}_{6} \mathrm{~F}_{5}$ in ${ }^{13} \mathrm{C}$ NMR spectra could not be obtained due to insufficient intensity of signals and nuclear coupling. ${ }^{19} \mathrm{~F}$ NMR $\left(\delta, \mathrm{ppm}, \mathrm{CDCl}_{3}\right):-124.56-(-124.73)(\mathrm{m}, 2 \mathrm{~F}),-149.48-$ $(-149.60)(\mathrm{m}, 1 \mathrm{~F}),-159.21-(-159.33)(\mathrm{m}, 2 \mathrm{~F})$. UV/visible absorption $\left(\mathrm{CH}_{2} \mathrm{Cl}_{2}, \lambda_{\max }\right.$ in $\mathrm{nm}(\varepsilon$ in $\left.\left.\mathrm{M}^{-1} \mathrm{~cm}^{-1}\right)\right): 246\left(2.1 \times 10^{4}\right)$. Anal. Calcd. for $\mathrm{C}_{38} \mathrm{H}_{21} \mathrm{~F}_{15} \mathrm{Ge}_{3}\left(\mathrm{M}_{\mathrm{w}}\right.$ 980.4694): C, 46.55; H, 2.16 . Found: C, 46.12; H, 1.88 .

Crystals suitable for X-ray diffraction analysis were obtained from $n$-hexane at $-30{ }^{\circ} \mathrm{C}$.

[Ph3 $\left.{ }_{3} G_{e G e M e}\right]_{2} G e\left(C_{6} F_{5}\right)_{2}$ (4). The procedure is the similar used for the synthesis of 3 using two equivalents of compound 2. Target compound $4(0.55 \mathrm{~g}, 84 \%)$ was obtained as a white powder after crystallization form $n$-hexane/toluene mixture, m.p. 206-207 ${ }^{\circ} \mathrm{C} .{ }^{1} \mathrm{H}$ NMR $(\delta$, ppm, $\left.\mathrm{CDCl}_{3}\right)$ : 7.34-7.31 (m, $6 \mathrm{H}$, aromatic protons), 7.26-7.21 (m, 24H, aromatic protons), 0.71 $\left(\mathrm{s}, 12 \mathrm{H}, 2 \mathrm{GeMe}_{2}\right) .{ }^{13} \mathrm{C} \mathrm{NMR}\left(\delta, \mathrm{ppm}, \mathrm{CDCl}_{3}\right): 136.53$ (quaternary aromatic carbon), 134.79, 128.13 ( $m$ - and $o-C H$ aromatic carbons), 128.76 ( $p-C H$ aromatic carbon), -0.52 $\left(\mathrm{GeMe}_{2}\right)$. The signals of $\mathrm{C}_{6} \mathrm{~F}_{5}$ in ${ }^{13} \mathrm{C}$ NMR spectra could not be obtained due to insufficient intensity of signals and nuclear coupling. ${ }^{19} \mathrm{~F}$ NMR $\left(\delta, \mathrm{ppm}, \mathrm{CDCl}_{3}\right)$ : -121.14 - (-121.23) (m, 2F), -152.29 - ($152.43)(\mathrm{m}, 1 \mathrm{~F}),-159.29-(-159.45)(\mathrm{m}, 2 \mathrm{~F})$. UV/visible absorption $\left(\mathrm{CH}_{2} \mathrm{Cl}_{2}, \lambda_{\max }\right.$ in $\mathrm{nm}\left(\varepsilon\right.$ in $\mathrm{M}^{-}$ 
$\left.\left.{ }^{1} \mathrm{~cm}^{-1}\right)\right): 267\left(4.5 \times 10^{4}\right)$. Anal. Calcd. for $\mathrm{C}_{52} \mathrm{H}_{42} \mathrm{~F}_{10} \mathrm{Ge}_{5}\left(\mathrm{M}_{\mathrm{w}}\right.$ 1220.0739): C, 51.19; H, 3.47 . Found: C, 51.06; H, 3.62.

Crystals suitable for $\mathrm{X}$-ray diffraction analysis were obtained from saturated $n$ hexane $/ \mathrm{CH}_{2} \mathrm{Cl}_{2}$ mixture at $-30{ }^{\circ} \mathrm{C}$.

\section{References}

[1] K. V. Zaitsev, A. V. Churakov, O. K. Poleshchuk, Y. F. Oprunenko, G. S. Zaitseva, S. S. Karlov, Dalton Transactions 2014, 43, 6605-6609.

[2] K. V. Zaitsev, V. A. Tafeenko, Y. F. Oprunenko, A. V. Kharcheva, Z. Zhanabil, Y. Suleimen, K. Lam, V. B. Zaitsev, A. V. Zaitseva, G. S. Zaitseva, S. S. Karlov, Chemistry - An Asian Journal 2017, 12, 1240-1249.

[3] aC. Marschner, in Functional Molecular Silicon Compounds I, Vol. 155 (Ed.: D. Scheschkewitz), Springer International Publishing, 2014, pp. 163-228; bC. Marschner, 2013.

[4] aL. R. Sita, in Advances in Organometallic Chemistry, Vol. Volume 38 (Eds.: F. G. A. Stone, W. Robert), Academic Press, 1995, pp. 189-243; bS. Adams, M. Dräger, B. Mathiasch, Journal of Organometallic Chemistry 1987, 326, 173-186.

[5] aM. L. Amadoruge, C. S. Weinert, Chemical Reviews 2008, 108, 4253-4294; bC. Marschner, J. Hlina, in Comprehensive Inorganic Chemistry II (Second Edition) (Eds.: J. Reedijk, K. Poeppelmeier), Elsevier, Amsterdam, 2013, pp. 83-117.

[6] aS. Kobayashi, S. Cao, Chem. Lett. 1993, 22, 1385-1388; bS. M. Katz, J. A. Reichl, D. H. Berry, Journal of the American Chemical Society 1998, 120, 9844-9849; cM. Okano, K.-i. Takeda, T. Toriumi, H. Hamano, Electrochimica Acta 1998, 44, 659-666; dM. Motonaga, H. Nakashima, S. Katz, D. H. Berry, T. Imase, S. Kawauchi, J. Watanabe, M. Fujiki, J. R. Koe, Journal of Organometallic Chemistry 2003, 685, 44-50; eJ. A. Reichl, C. M. Popoff, L. A. Gallagher, E. E. Remsen, D. H. Berry, Journal of the American Chemical Society 1996, 118, 9430-9431; fS. Kashimura, M. Ishifune, N. Yamashita, H.-B. Bu, M. Takebayashi, S. Kitajima, D. Yoshiwara, Y. Kataoka, R. Nishida, S.-i. Kawasaki, H. Murase, T. Shono, The Journal of Organic Chemistry 1999, 64, 6615-6621.

[7] aK. Häberle, M. Dräger, Z. Anorg. Allg. Chem. 1987, 551, 116-122; bK. Haberle, M. Drager, Zeitschrift Fur Naturforschung Section B-a Journal of Chemical Sciences 1987, 42, 323-329.

[8] A. Castel, P. Riviere, B. Saintroch, J. Satge, J. P. Malrieu, Journal of Organometallic Chemistry 1983, 247, 149-160.

[9] aJ. Fischer, J. Baumgartner, C. Marschner, Organometallics 2005, 24, 1263-1268; bJ. Hlina, J. Baumgartner, C. Marschner, Organometallics 2010, 29, 5289-5295; cJ. Hlina, R. Zitz, H. Wagner, F. Stella, J. Baumgartner, C. Marschner, Inorganica Chimica Acta 2014, 422, 120-133.

[10] K. V. Zaitsev, A. A. Kapranov, A. V. Churakov, O. K. Poleshchuk, Y. F. Oprunenko, B. N. Tarasevich, G. S. Zaitseva, S. S. Karlov, Organometallics 2013, 32, 6500-6510.

[11] aS. Roller, M. Dräger, Journal of Organometallic Chemistry 1986, 316, 57-65; bM. Drager, D. Simon, Journal of Organometallic Chemistry 1986, 306, 183-192.

[12] M. L. Amadoruge, A. G. DiPasquale, A. L. Rheingold, C. S. Weinert, Journal of Organometallic Chemistry 2008, 693, 1771-1778.

[13] K. V. Zaitsev, K. Lam, Z. Zhanabil, Y. Suleimen, A. V. Kharcheva, V. A. Tafeenko, Y. F. Oprunenko, O. K. Poleshchuk, E. K. Lermontova, A. V. Churakov, Organometallics 2017, 36, 298-309.

[14] K. D. Roewe, J. A. Golen, A. L. Rheingold, C. S. Weinert, Canadian Journal of Chemistry 2014, 92, 533-541.

[15] C. R. Samanamu, M. L. Amadoruge, C. H. Yoder, J. A. Golen, C. E. Moore, A. L. Rheingold, N. F. Materer, C. S. Weinert, Organometallics 2011, 30, 1046-1058. 
[16] E. K. Schrick, T. J. Forget, K. D. Roewe, A. C. Schrick, C. E. Moore, J. A. Golen, A. L. Rheingold, N. F. Materer, C. S. Weinert, Organometallics 2013, 32, 2245-2256.

[17] aR. D. Miller, J. Michl, Chemical Reviews 1989, 89, 1359-1410; bC. Marschner, J. Baumgartner, A. Wallner, Dalton Transactions 2006, 5667-5674.

[18] aK. V. Zaitsev, A. A. Kapranov, Y. F. Oprunenko, A. V. Churakov, J. A. K. Howard, B. N. Tarasevich, S. S. Karlov, G. S. Zaitseva, Journal of Organometallic Chemistry 2012, 700, 207-213; bK. V. Zaitsev, Y. F. Oprunenko, A. V. Churakov, G. S. Zaitseva, S. S. Karlov, Main Group Metal Chemistry 2014, 37, 67-74; cK. V. Zaitsev, E. K. Lermontova, A. V. Churakov, V. A. Tafeenko, B. N. Tarasevich, O. K. Poleshchuk, A. V. Kharcheva, T. V. Magdesieva, O. M. Nikitin, G. S. Zaitseva, S. S. Karlov, Organometallics 2015, 34, 2765-2774.

[19] E. Subashi, A. L. Rheingold, C. S. Weinert, Organometallics 2006, 25, 3211-3219.

[20] aK. Betka, J. Grobe, Journal of Organometallic Chemistry 1981, 210, 19-36; bC. H. Yoder, D. R. Griffith, C. D. Schaeffer, Journal of Inorganic and Nuclear Chemistry 1970, 32, 3689-3691.

[21] M. Drager, L. Ross, Z. Anorg. Allg. Chem. 1980, 469, 115-122.

[22] M. C. C. Ng, D. J. Craig, J. B. Harper, L. van-Eijck, J. A. Stride, Chemistry-a European Journal 2009, $15,6569-6572$.

[23] M. L. Amadoruge, E. K. Short, C. Moore, A. L. Rheingold, C. S. Weinert, Journal of Organometallic Chemistry 2010, 695, 1813-1823.

[24] S. Roller, D. Simon, M. Drager, Journal of Organometallic Chemistry 1986, 301, 27-40.

[25] C. R. Samanamu, M. L. Amadoruge, A. C. Schrick, C. Chen, J. A. Golen, A. L. Rheingold, N. F. Materer, C. S. Weinert, Organometallics 2012, 31, 4374-4385.

[26] S. P. Komanduri, F. A. Shumaker, K. D. Roewe, M. Wolf, F. Uhlig, C. E. Moore, A. L. Rheingold, C. S. Weinert, Organometallics 2016, 35, 3240-3247.

[27] K. D. Roewe, A. L. Rheingold, C. S. Weinert, Chemical Communications 2013, 49, 8380-8382.

[28] M. Okano, K. Mochida, Chem. Lett. 1990, 701-704.

[29] Y. Huo, D. H. Berry, Chemistry of Materials 2005, 17, 157-163.

[30] M. L. Amadoruge, J. R. Gardinier, C. S. Weinert, Organometallics 2008, 27, 3753-3760.

[31] K. Mochida, C. Hodota, R. Hata, S. Fukuzumi, Organometallics 1993, 12, 586-588.

[32] aR. J. Batchelor, T. Birchall, Journal of the American Chemical Society 1983, 105, 3848-3852; bK. B. Clark, D. Griller, Organometallics 1991, 10, 746-750. 


\section{Highlights}

-the first oligogermyl amide, $\mathrm{Ph}_{3} \mathrm{GeGeMe}_{2} \mathrm{NMe}_{2}$, was synthesized

-novel tri- and pentagermanes donor-acceptor type were obtained and studied

-these compounds are luminescent and electrochemically active

-the physical properties of oligogermanes depend on median or end type of substitution -unpolar oligogermanes, in a crystal, form cavities that could trap organic compounds

\section{Graphical Abstract}

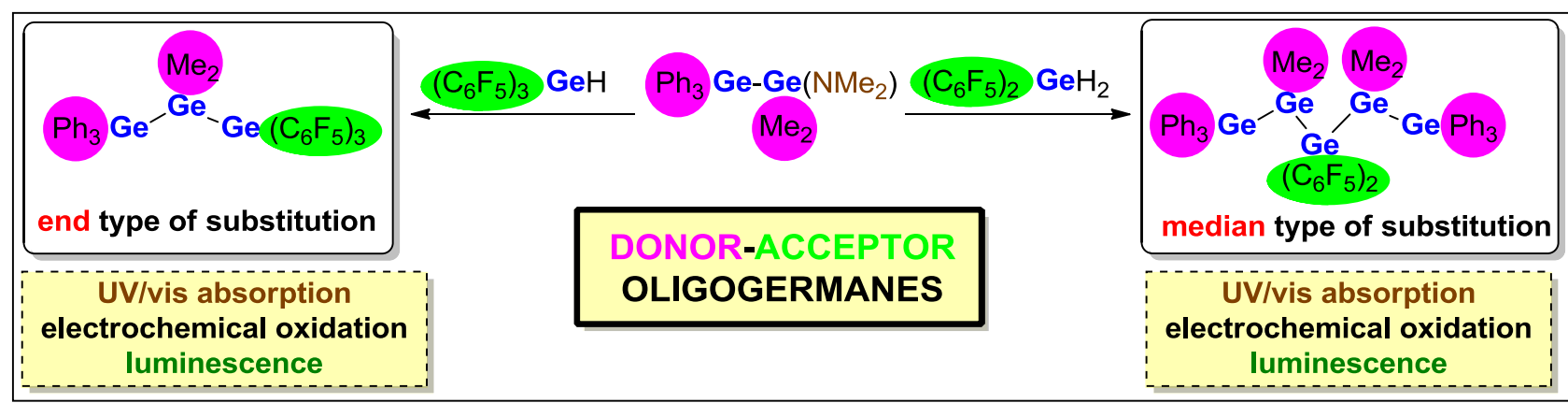

